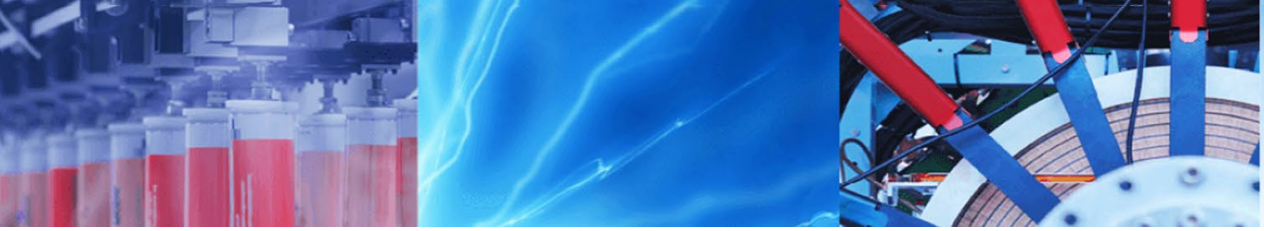

Research Article

\title{
Imperfection-sensitivity of unanchored aboveground open-top steel welded liquid storage tanks subjected to seismic loads
}

\author{
J. M. Spritzer ${ }^{1}$ H. Bohra² S. Guzey²
}

Received: 7 February 2019 / Accepted: 31 October 2019 / Published online: 7 November 2019

(c) Springer Nature Switzerland AG 2019

\begin{abstract}
A numerical analysis is conducted on several unanchored aboveground, open-top, steel, welded, liquid-containing storage tanks with imperfections subjected to seismic forces. Nonlinear material properties, nonlinear geometry deformations, and a flexible soil foundation idealized by a series of elastic springs are employed in order to simulate as-built field conditions of the tank at the time of the seismic event. A static pushover analysis was performed using impulsive and convective hydrodynamic effects of fluid contained in the tank subject to seismic motion modeled as an equivalent pressure distribution acting on the tank wall and base. Out-of-plumbness (OOP) imperfections, which is the deviation of the top of the tank shell with respect to the shell-to-base connection, and out-of-roundness (OOR) imperfections, which is a deviation in a given shell course with respect to the undeformed shell configuration, are implemented into the tanks to observe the comparative behavior when between perfect and imperfect tanks. The tolerances for construction prescribed by American Petroleum Institute (API) and recommended by the New Zealand Society of Earthquake Engineering (NZSEE) are used for the amplitude of the imperfections. In a worst case scenario, the OOP and OOR imperfections are combined. The analysis shows that the behavior of the tanks with imperfections using the API 650 tolerances show little deviation from the perfect tank conditions, and in some instances, even out-perform the perfect shell conditions, and thus shell imperfections when they are within the specified tolerances of relevant standard of construction pose little additional threat to the tank when experiencing a seismic event.
\end{abstract}

Keywords Aboveground storage tank · Seismic analysis · Imperfections · Nonlinear numerical evaluation · API $650 \cdot$ Outof-plumbness · Out-of-roundness · Circular cylindrical shell

\section{Introduction}

Behavior of large aboveground steel welded open-top liquid containing storage tanks excited by seismic loads has been examined extensively over the past several decades and is rather well understood. Housner is credited as the one of the first investigators to develop an intuitive tool for the design and analysis of these types of tanks [1-4]. His model, widely referred to as the "spring-mass" analogy, divides the tank system response due to seismic accelerations into two effective hydrodynamic forces: the impulsive and convective modes (Fig. 1). The former consists of a portion of the liquid the moves in uniformity with the tank. The latter contains forces that move out of sync with the tank and which create sloshing washes against the wall of the tank-the convective mode is synonymously referred to as the sloshing mode. The period of motion for the impulsive and convective modes, respectively, are generally in the range of $0.1-0.2 \mathrm{~s}$ and $5-10 \mathrm{~s}$ depending on tank parameters such as diameter, wall thickness, liquid height and liquid density. As such, it is clear that the response of the two modes are drastically

S. Guzey, guzey@purdue.edu| ${ }^{1}$ Matrix PDM Engineering, Pittsburgh, PA, USA. ${ }^{2}$ Lyles School of Civil Engineering, Purdue University, West Lafayette, IN, USA. 


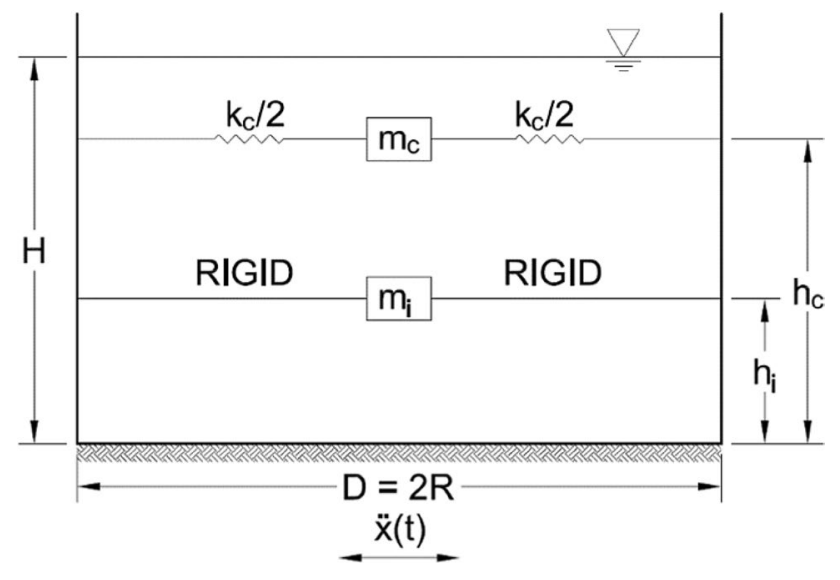

Fig. 1 Spring-mass analogy produced by Housner $[3,4]$

different. The forces generated from the impulsive modes are typically much greater than those of the convective modes, and therefore, the impulsive modes are critical to the response of the tank from a strength standpoint. Sloshing forces, however, can induce vertical and horizontal forces on the tank, and if present, the roof of the tank leading to plastic damage and even rupture. Moreover, the sloshing waves pose a potential issue of the liquid spilling over the top of the tank wall. Housner's spring-mass model is still widely used and is the basis of the design specification in Annex E (the seismic design provisions) of API 650 developed by the American Petroleum Institute (API) [5].

While Housner's approach is simple and convenient, there are a few short-comings. First, the model assumes that the tank walls are unable to deform with respect to its undeformed configuration. This idealization can simply not be achieved in real-life applications. Second, the tank is assumed to remain rigidly attached to the base foundation during the seismic event. For tanks that are connected to their foundation using anchor straps, this assumption may be acceptable. Many researchers have studied the effects of uplifting and flexible tanks subjected to seismic forces in order to develop a useful design tool incorporating these effects [6-16]. Natsiavas and Babcock $[12,13]$ determined that the behavior of uplifting and flexible tanks is not the same as a rigid tank through experimental and analytical testing. For tanks with an unanchored base connection, typically referred to as "self-anchored" tanks, base uplift and rotation may occur as a result of the horizontal seismic forces [11]. Because of potential base uplift, unanchored tanks may be more adversely effected from imperfections than anchored tanks. For this reason, only unanchored tanks will be analyzed in this work.

Housner's model also does not consider nonlinear material properties and nonlinear geometry deformations. Several researchers have investigated the effects of nonlinear uplifting tanks [14, 17-30]. One particular area of concern for nonlinear tanks subjected to seismic forces is elephant's foot buckling. Elephant's foot buckling occurs when very large hydrostatic and hydrodynamic tensile hoop stresses close to yield point act concurrently with axial compressive stresses exceeding critical stress on the shell wall. This loading scenario, which are generated in a tank shell during seismic events, can lead to extensive plastic deformations near the base-to-shell connection. On the reverse side of the tank to the elephant's foot buckle, base uplift tends to occur as the momentum of contained liquid acts on the shell wall, resulting in overturning forces. It has been shown that the recommended uplift for piping connections and attachments provided by API 650 at the base-to-shell connection for uplifting tanks does not compare well with analytical models under seismic loads [27]. In addition to elephant's foot buckling, tanks may buckle in the form of diamond-shaped buckles due to a seismic excitation. Diamond shaped buckling typically observed in very thin tanks such as stainless steel wine storage tanks (NZSEE) [31]. Vathi and Karamanos [14] also showed that the uplift can result in premature buckling due to increase in axial compression.

Due to the complex nature of nonlinear, uplifting, flexible tanks, many researchers have developed modified models of Housner's approach in order to accommodate the nonlinear materials and geometry effects for tanks under seismic loads. Maheri et al. [21] studied the natural and rocking frequencies for unanchored, flexible tanks and developed a procedure to accurately estimate the frequencies for tanks with any geometry. Virella et al. [29] studied several tank failures using a nonlinear static procedure (NLSP) and were able to estimate the critical peak ground acceleration (PGA) that caused failure of tanks experiencing buckling near the roof-to-shell connection. El-Zeiny [18] used the finite element method for the analysis of such tanks including fluid-structure interaction effects with a dynamic time history analysis. Buratti and Tavano [32] studied the failure of tanks in the past using an extensive database in order to develop seismic fragility curves which may estimate the future failure of anchored tanks under seismic loads. Phan et al. [33] studied the seismic vulnerability using probabilistic seismic risk assessment and developed the fragility curves for tank failure under seismic loads. Bakalis et al. [34] developed fragility curves for storage tanks using a simplified nonlinear static pushover procedure and showed that the results agree with the incremental dynamic analysis. Meanwhile, Vathi et al. [35] recommended a performance-based design (PBD) criteria for seismic design of tanks and piping systems. Further, Vathi and Karamanos [36] investigated the fatigue failure of the tank bottom and shell connection due to uplifting under seismic load. They developed a simplified and 
efficient model to conduct fatigue assessment of uplifting storage tanks. These new and improved methods for determining the behavior of nonlinear, uplifting, flexible tanks provide more accurate solutions for tanks under seismic loads. Despite this fact, it has been shown that provisions set by API 650 for seismic design provide suitable results using Housner's model which assumes rigid walls and a rigid base with elastic materials [27].

One topic relating to the behavior of storage tanks that has not been studied extensively is the inclusion of shell imperfections coupled with seismic forces. Shell imperfections appear in many forms and are typically a result of low quality construction. By introducing geometric imperfections into a perfect shell, local stress concentrations can develop at the location of the imperfection, leading to local and even global failure. From a mechanics point of view, the hydrostatic pressure acting on the tank due to the contained liquid will eventually help to reduce the imperfections in a newly constructed tank by keeping the shell in constant tensile membrane stress. However, the imperfections will not be alleviated completely, and thus still pose a concern to the tank system. Therefore, insight can be gained by exploring the effects of shell imperfections and by comparing the behavior to tanks without imperfections.

The topic of the effect of imperfections on the critical buckling load for a shell in pure axial compression has been rather well studied. Koiter is considered one of the earliest researchers to develop work in this area [37-39]. Koiter and many other researchers pointed out that the buckling strength of a shell in axial compression is very sensitive to even minimal geometric imperfections and that the imperfections will reduce the critical buckling load of the shell [37-44]. Koiter et al. [39] showed that an imperfection amplitude of one shell thickness, which is usually on the order of one one-thousandth or less of the tank radius, reduced the buckling strength of a shell in axial compression by at least $20 \%$. The sensitivity of the imperfection is also dependent on the type of imperfection introduced into the tank and on the height of the shell [41-43]. For example, axisymmetric sinusoidal imperfection pattern and an asymmetric imperfection pattern will not behave similarly; tanks with the same sinusoidal imperfection pattern but different wavelengths will have dissimilar responses. Thus, it is apparent that the inclusion of imperfections into a perfect tank shell can have negative impacts to a certain extent on the strength capacity of the tank. Moreover, it is difficult to accurately quantify the reduction in the shell strength resulting from an imperfection due to the number of variables influencing the imperfection response. It should also be reinforced here that this literature is for shells in axial compression with rigid or pinned base conditions.
Godoy and Flores [40] showed that the buckling capacity of the tank shell subjected to external wind forces was reduced with the inclusion of imperfections. Godoy and Flores used a bifurcation buckling analysis to determine the buckling load and buckling mode shape which was then introduced into their finite element models; this method to determine the dominant buckling shape has been most widely used for imperfection analysis for several decades. Their results showed as the imperfection amplitude, was increased, the buckling capacity of the shell decreased for the same wind loading. Moreover, as the aspect ratio decreased, which is the ratio of the height to the radius, the more sensitive the tanks were to the geometric imperfection. Veletsos and Turner [44] showed that the differences in the estimated and true response of experimentally tested tanks subjected to seismic loads were attributed to imperfections in the test tanks. Djermane et al. [45] studied the effect of sinusoidal pattern imperfections for tanks subjected to seismic forces using a time-history analysis for non-uplifting tanks and compared the results from the finite element analysis to European and American Water Works Association design standards.

API 650 identifies several shell imperfections that can result during construction and erection. The two main imperfections corresponding to the shell only are outof-plumbness (OOP) and out-of-roundess (OOR). Out-ofplumbness is a relative displacement of the top of the tank shell to the bottom of the shell. Out-of-roundness is the relative radial displacement with respect to the perfect tank configuration. Figure 2 shows OOP and OOR imperfections for any arbitrary tank. Several other "local deviations" can also result at the location of the shell-to-shell welds. Peaking and banding are the deviations in vertical and horizontal welds, respectively. Each of these shell imperfections have specific allowances that must be met during the construction phase. The allowances are mainly set for the proper functioning of floating roofs. The effects of imperfections are not explicitly included in the seismic provisions of API 650 Annex E, however. Rotter [41] has developed a simple expression, which was based on judgement, to estimate the imperfection amplitude due to construction imperfections which takes into account the tank's radius, thickness, and quality of construction. The New Zealand Society of Earthquake Engineering (NZSEE), which is the prominent design guide for steel tanks subjected to seismic loads in New Zealand, prescribes a strength reduction in the axial compression capacity of the tank due to seismic forces due to imperfections in the shell using Rotter's expression (NZSEE) [31]. Therefore, due to the fact that shell imperfections can have a significant impact on the buckling capacity of the tank, and due to the fact that other design guides have acknowledged this phenomena, it appears API 650 may also need to explicitly 

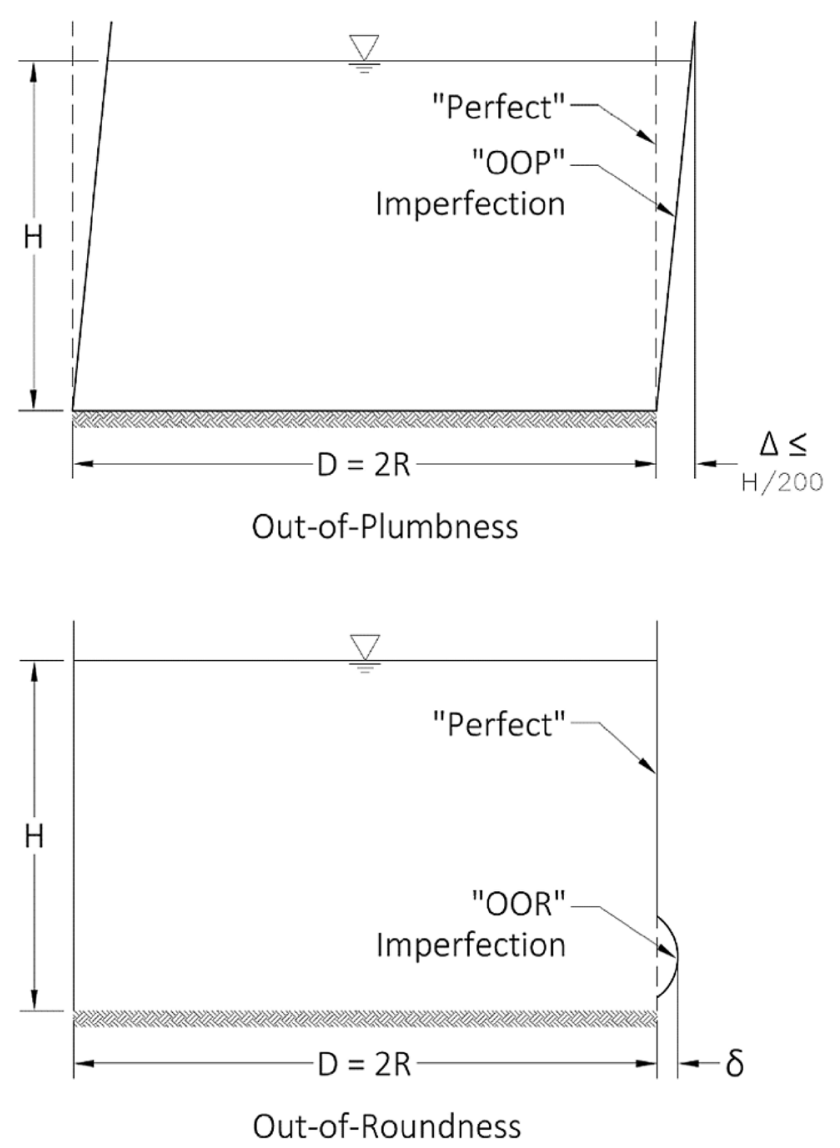

Fig. 2 Out-of-plumbness (OOP) and out-of-roundness (OOR) shell imperfections

include the effects of imperfections in the seismic provisions rather than the indirect approach of relying on available construction tolerances.

The objective of this report is to evaluate the response of several steel, welded, open-top, flat-bottom, liquidcontaining storage tanks subjected to seismic forces with imperfect shells compared to identical shells with perfect shells. Moreover, recommendations will be made to API 650 regarding shell imperfections based on the results of the analysis. A static pushover analysis was performed using impulsive and convective hydrodynamic effects of fluid contained in the tank subject to seismic motion modeled as an equivalent pressure distribution acting on the tank wall and base. Finite element analysis (FEA) using the finite element package, Abaqus CAE 2016 [46], was conducted with nonlinear material properties and nonlinear geometry deformations. The tanks chosen for this study have varying aspect ratios, which is the ratio of the tank height to radius, from 1.0 to 2.8 . The tanks were assumed to be self-anchored and are supported by an elastic soil foundation which is modeled as a series of elastic springs. The API 650 does not require mechanical anchorage for
Table 1 Tank identification, geometries, and aspect ratio (H/R)

\begin{tabular}{llll}
\hline Tank ID & Height $(\mathrm{ft})^{\text {a }}$ & Radius $(\mathrm{ft})^{\mathrm{a}}$ & $\begin{array}{l}\text { Aspect } \\
\text { ratio } \\
(\mathrm{H} / \mathrm{R})\end{array}$ \\
\hline 1 & 40 & 40 & 1.0 \\
2 & 56 & 40 & 1.4 \\
3 & 40 & 20 & 2.0 \\
4 & 56 & 20 & 2.8 \\
\hline
\end{tabular}

${ }^{\mathrm{a}}$ To convert to meters, multiply value in table by 0.3048

seismic purposes, provided that the anchorage ratio $J$ is not more than 1.54. The anchorage ratio $J$ depends on the seismic acceleration parameters. Therefore, the assumption of self-anchored tank holds true up to a certain percentage of applied maximum seismic load level. Further details on anchorage ratio $J$ for each tank are given in Sect. 2.3. OOP and OOR imperfections were chosen due to their prevalence during construction; the welds between the tank walls were not included in the models and thus weld imperfections were not included in this report. As a worst case scenario, the OOP and OOR imperfections were modeled simultaneously. The amplitude of the shell imperfections were set to match the limits set by API 650's construction tolerances. Larger amplitudes were investigated to determine the increased effect of the imperfections on the seismic response of the tank.

\section{Methods}

This section discusses all aspects of the design of the tanks and their subsequent finite element models (FEMs). The tank design consists of the shell wall, base and annular plates, and wind girders. As mentioned previously, the welds were not included into the models, nor were weld imperfections. The tank design is followed by a discussion of the selected seismic demand and assumed field conditions. The FEMs representing the actual tank system, which consist of both perfect and imperfect shells with OOP and OOR imperfections, are then explained.

\subsection{Tank design}

In order to study various aspect ratios, two tank heights and two tank radii were chosen for four different tank sizes with aspect ratios between 1.0 and 2.8. These four tanks will also provide insight as to how the tank radius effects the behavior of the tank with shell imperfections. Each of the tanks and their corresponding heights and radii are provided in Table 1. Tank heights were selected as 
multiples of $8 \mathrm{ft}(2.4 \mathrm{~m})$ shell courses, which are the most commonly shell course heights in the United States.

The shell wall was assumed to be ASTM A516 Grade 70 steel which has a yield strength, $F_{y^{\prime}}$ design product stress, $\mathrm{S}_{\mathrm{d}}$, and hydrostatic test stress, $\mathrm{S}_{\mathrm{t}}$, of 38,000 psi (260 MPa), $25,300 \mathrm{psi}(173 \mathrm{MPa})$, and 28,500 psi (195 MPa), respectively [47]. The base, annular ring, and wind girders were assumed to be ASTM A36 steel which has a yield strength, $F_{y}$, of 36,000 psi (250 MPa) [48]. ASTM A516 Grade 70 steel and $A 36$ steel were assumed to have ultimate tensile strengths, $F_{u^{\prime}}$ of 70,000 psi $(485 \mathrm{MPa})$ and 58,000 psi (400 MPa), respectively. Both steels have a Young's Modulus, E, of 29,000 ksi (200 GPa) and Poisson's ratio, v, of 0.3. The liquid contained in the tank was assumed to have a specific gravity of 0.9 for design conditions and 1.0 for hydrostatic test conditions. The tanks were initially designed assuming elastic material properties. The nonlinear material properties will be discussed later and were used only for the seismic analysis.

Prior to analyzing the tank under seismic loads, the tank shell must first be designed for the gravity and hydrostatic conditions at ambient temperatures. The shell for the tank was designed using Chapter 5 of API 650, which contains of the guidelines for the design of the tank shell thickness for hydrostatic loads. The 1-Foot Method and VariableDesign-Point Method were both used for hydrostatic test and design conditions; the most economical set of shell thickness from the two methods was chosen as the final shell design. The design shell thicknesses for each of the tanks and their base thicknesses are provided in Table 2. It should be noted that API 650 limits the base shell course for tanks with diameters between $10.5(3.2 \mathrm{~m})$ and $50 \mathrm{ft}$ $(15 \mathrm{~m})$ to be no less than $0.25 \mathrm{in}$. $(6 \mathrm{~mm})$. Therefore, this limit was applied to Tanks 3 and 4. Moreover, API 650 limits the thickness of any shell course for tanks with diameters less than $50 \mathrm{ft}(15 \mathrm{~m})$ to $0.188 \mathrm{in} .(5 \mathrm{~mm})$ and for tanks with diameters between $50(15 \mathrm{~m})$ and $120 \mathrm{ft}(36 \mathrm{~m})$ to 0.25 in. $(6 \mathrm{~mm})$. Both of these shell thickness limitations were satisfied, as shown in Table 2. This table provides calculated minimum required plate thickness values in three decimal points following the convention used in Annex K of API 650. Although, some of the plate thicknesses such as 0.289 in., 0.407 in. and 0.345 in. may not be readily available in the market, they can be ordered directly from the steel mills in North America provided that they are ordered in sufficiently large quantities, typically larger than 20 tons.

The bottom plate shell thickness was designed according to Section 5.4 of API 650. The minimum base thickness for any tank is 0.25 in. $(6 \mathrm{~mm})$, which is the base thickness used for each tank. The annular ring thickness was designed according to Section 5.5 of API 650 . The maximum stress in the first shell course under product stress and hydrostatic test stress, along with the thickness of the first shell course, dictates the minimum annular plate thickness. For all tanks, the annular ring minimum thickness was 0.25 in. $(6 \mathrm{~mm})$. Therefore, the thickness of the annular ring was equal to the base plate thickness.

Another design aspect of the tank that needs to be accounted for are the wind girders. In reality, a top wind girder will be provided on the tank to provide stiffness to the top of the tank when wind acts on the side of the tank. While wind forces were not considered in this analysis, wind girders were included in the models in order to limit the amount of ovalization of the tank when the tank is acted on by seismic forces. Therefore, the wind girders for each of the tank were designed according to Section 5.9 of API 650 using a 3-s design wind gust of $90 \mathrm{mph}$ ( $143 \mathrm{~km} / \mathrm{h}$ ). This section of API 650 requires that the shell be analyzed for both top wind girders and intermediate wind girders, which are located between the bottom of the shell and the top wind girder. It was determined that all of the tanks did not need intermediate wind girders due to the geometry and shell thickness, and thus only top wind girders were provided. The minimum required and provided section moduli of the wind girder for each tank, and the dimensions and type of the wind girder, are provided in Table 3. Figure 3 shows the detailing of the wind girders that are specified by API 650 that were used for the tanks in this report. Each of the wind girders was designed to be located $6 \mathrm{in} .(15 \mathrm{~cm})$ below the top of the tank. The angle sections used as a top wind girder for tanks 3 and 4 were attached to the tank shell in short leg vertical orientation.

It should be noted that tanks must be considered for stability under wind loads. Three critical scenarios exist that API 650 identifies in paragraph 5.11.2.1 and requires to be
Table 2 Final design shell and base thicknesses for each tank in inches

\begin{tabular}{lllllllll}
\hline Tank ID & Course 1 & Course 2 & Course 3 & Course 4 & Course 5 & Course 6 & Course 7 & Base \\
\hline 1 & 0.289 & 0.250 & 0.250 & 0.250 & 0.250 & - & - & 0.250 \\
2 & 0.407 & 0.345 & 0.287 & 0.250 & 0.250 & 0.250 & 0.250 & 0.250 \\
3 & 0.250 & 0.188 & 0.188 & 0.188 & 0.188 & - & - & 0.250 \\
4 & 0.250 & 0.188 & 0.188 & 0.188 & 0.188 & 0.188 & 0.188 & 0.250 \\
\hline
\end{tabular}

To convert shell thicknesses from inches to millimeters, multiply values in table by 25.4 Course 1 is the bottom shell course. Course numbers increase with increasing tank height 
Table 3 Top wind girder details and design dimensions

\begin{tabular}{llllll}
\hline Tank ID & $\begin{array}{l}\text { Req'd. section } \\
\text { modulus }\left(\mathrm{in}^{3}\right)^{\mathrm{a}}\end{array}$ & $\begin{array}{l}\text { Prov'd. section } \\
\text { modulus }\left(\mathrm{in}^{3}\right)^{\mathrm{a}}\end{array}$ & $\begin{array}{l}\text { Wind girder } \\
\text { type }\end{array}$ & $\begin{array}{l}\text { Angle size (in) } \\
\text { b }\end{array}$ & $\begin{array}{l}\text { Leg “b” }^{\text {" }} \\
\text { size } \\
\text { (in) }\end{array}$ \\
\hline 1 & 14.4 & 17.6 & $\mathrm{e}$ & - & 8 \\
2 & 20.2 & 23.3 & $\mathrm{e}$ & - & 10 \\
3 & 3.60 & 4.14 & $\mathrm{c}$ & $4 \times 3 \times 5 / 16$ & - \\
4 & 5.04 & 5.53 & $\mathrm{c}$ & $5 \times 3 \times 5 / 16$ & - \\
\hline
\end{tabular}

${ }^{\text {a }}$ To convert section modulus from cubic inches to cubic centimeters, multiply values in table by 16.4

${ }^{\mathrm{b}}$ To convert angle sizes from inches to millimeters, multiply values in table by 25.4

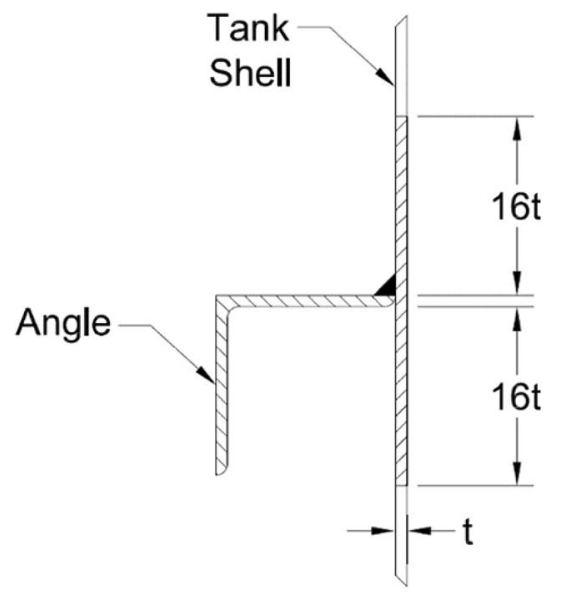

Detail "c"

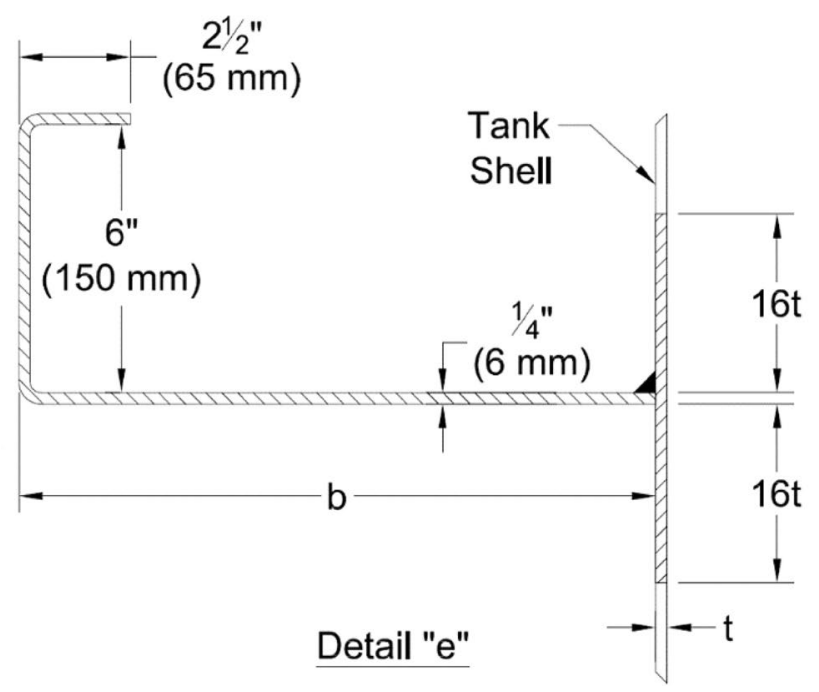

Fig. 3 Top wind girder details assessed. These three scenarios are described by the following expressions

(i) $0.6 M_{w}+M_{P i}<\frac{M_{D L}}{1.5}+M_{D L R}$

(ii) $M_{w}+F_{p}\left(M_{P i}\right)<\frac{\left(M_{D L}+M_{F}\right)}{2}+M_{D L R}$

(iii) $M_{w s}+F_{p}\left(M_{P i}\right)<\frac{M_{D L}}{1.5}+M_{D L R}$

where $M_{w}$ is the overturning moment due to wind pressure on shell and roof, $M_{P i}$ is the overturning moment due to design internal pressure, $F_{p}$ is internal pressure load combination factor which is typically $0.4, M_{w s}$ is the overturning moment due to wind pressure on shell, $M_{D L}$ is the resisting moment due to self-weight of shell, $M_{D L R}$ is the resisting moment due to roof and $M_{F}$ is the resisting moment due to liquid weight. The magnitude of the overturning forces (wind and internal pressure) must be less than the resisting forces (dead weight of tank, roof, and liquid), when acting at a pivot point at the shell-tobottom joint. If this equilibrium condition is not satisfied, anchor straps must be used to hold the tank down. The internal roof pressure and resisting weight of the floating roof were set to zero since the tanks analyzed in this report are open-top tanks. It was determined that only one of the three scenarios, namely the scenario iii in above expression, would control for the tanks analyzed in this report which consists of a full wind gust ( $90 \mathrm{mph}, 143 \mathrm{~km} / \mathrm{h}$ ) on the shell wall and two-thirds of the self-weight of the shell only (empty tank). The maximum tank heights that satisfies the API 650 overturning stability limits for tank radii of $20 \mathrm{ft}(6.1 \mathrm{~m})$ and $40 \mathrm{ft}(12.2 \mathrm{~m})$ are approximately $85 \mathrm{ft}$ $(25.9 \mathrm{~m})$ and $170 \mathrm{ft}(51.8 \mathrm{~m})$, respectively. Therefore, it can be concluded that each of the tanks used in this analysis satisfy the overturning stability requirements of API 650 . 


\subsection{Seismic demand}

The seismic demand used for this analysis was determined using the Mapped ASCE 7 Method (ASCE) [49] which is prescribed in Annex E of API 650. The Mapped ASCE 7 Method provides the spectral response accelerations for a given region with a $2 \%$ probability of exceedance for a 50 -year event return period. The spectral response accelerations are provided by ASCE 7 maps for 5\% damping. The short period spectral response parameter, $S_{s^{\prime}}$ and the 1-s spectral response parameter, $S_{1}$, were chosen for an arbitrary site, and have values of $1.36 \mathrm{~g}$ and $0.68 \mathrm{~g}$, respectively. The transition period for longer period ground motion, $T_{L}$, for the site location was also determined to be $4.0 \mathrm{~s}$. The spectral response parameters and transition period values were determined using the USGS "Worldwide Seismic Hazard Maps" for a location outside of the United States (USGS) [50]. This site was selected in order to remain consistent with the site chosen for two companion papers Spritzer and Guzey $[27,28]$. One other reason to select this location was to have a relatively large spectral response parameters to capture buckling of all the tanks selected. Note that, another location within the United States with similar response parameters could be found. Furthermore, the tanks are not designed to carry $100 \%$ seismic load.

The spectral response acceleration parameters need to be modified based on the anticipated soil conditions at the site of the tank. Since the type of soil was unknown, API 650 specifies a "Class D" soil to be used. A Class D soil is described as a "stiff soil with $600 \mathrm{ft} / \mathrm{s} \leq \mathrm{v}_{\mathrm{s}} \leq 1200 \mathrm{ft} / \mathrm{s}$ $\left(180 \mathrm{~m} / \mathrm{s} \leq \mathrm{v}_{\mathrm{s}} \leq 360 \mathrm{~m} / \mathrm{s}\right)$, or with either $15 \leq \mathrm{N} \leq 50$ or 1000 psf $\leq \mathrm{S}_{\mathrm{u}} \leq 2000$ psf $\left(50 \mathrm{kPa} \leq \mathrm{S}_{\mathrm{u}} \leq 100 \mathrm{kPa}\right)$," where $\mathrm{v}_{\mathrm{s}}$ is the soil shear wave velocity, $\mathrm{N}$ is the average Standard Penetration Resistance determined using ASTM D1586, and $S_{u}$ is the undrainded shear strength of the soil [51]. The soil amplification coefficients, $\mathrm{F}_{\mathrm{a}}$ and $\mathrm{F}_{\mathrm{v}}$ for Class $\mathrm{D}$ soil and for the given spectral response parameters, $S_{s}$ and $S_{1}$, are therefore determined to be 1.0 and 1.5 , respectively.

The spectral response accelerations are also modified to account for ductility, damping, and over-strength of the tank system. API 650 provides two factors, called the response modification factor, $R$, for the two modes, impulsive and convective, for reducing the corresponding effective forces applied to the tank. For self-anchored tanks, the response modification factors are 3.5 and 2.0, respectively.

The influence the tanks play on the surrounding environment and society in the case of a failure are also considered in the API 650 Annex E provisions and is represented by the "importance factor," I. The importance factor is determined based on the tank's "Seismic Use Group" (SUG), which in the instance of the tanks for this analysis, fall under SUG I; SUG I tanks are tanks that do not pose significant public hazard and are not critical for recovery
Table 4 Impulsive and convective time periods and acceleration coefficients

\begin{tabular}{lllll}
\hline Tank ID & $\mathrm{A}_{\mathrm{i}}(\mathrm{g})$ & $\mathrm{T}_{\mathrm{i}}(\mathrm{s})$ & $\mathrm{T}_{\mathrm{c}}(\mathrm{s})$ & $\mathrm{A}_{\mathrm{c}}(\mathrm{g})$ \\
\hline 1 & 0.260 & 0.22 & 5.20 & 0.073 \\
2 & 0.260 & 0.26 & 5.30 & 0.076 \\
3 & 0.260 & 0.18 & 3.66 & 0.140 \\
4 & 0.260 & 0.28 & 3.66 & 0.140 \\
\hline
\end{tabular}

after an earthquake has occurred. Therefore, the importance factor was determined to be 1.0 for SUG I.

All of the variables previously discussed are used to determine the individual impulsive and convective spectral response parameters, $A_{i}$ and $A_{c}$ respectively. As with traditional earthquake engineering for buildings, bridges and other structures in general, the response of the two modes are dependent on their respective period of motion. For the impulsive mode, the period of motion, $\mathrm{T}_{i}$, is typically between 0.1 and $0.3 \mathrm{~s}$, which falls on the plateau of the response spectra as shown in Table 4. The convective mode, on the other hand, has a much longer period of motion, $T_{c^{\prime}}$ and generally is outside of the plateau of the response spectra. Therefore, the period of motion for the convective mode is crucial for determining the convective response modification factor. The values of $A_{i}, T_{i}, T_{c}$, and $A_{c}$ were all calculated using the provisions of API 650 Annex E and are provided in Table 4. Further details of how to calculate the impulsive and convective spectral response parameters can be found in separate publications $[27,28,52]$.

The impulsive and convective response acceleration parameters are used to determine the effective hydrodynamic liquid pressures acting on the tank wall during the seismic event. One method to implement the effective pressures into the models is to apply the effective impulsive and convective masses used in the equivalent spring-mass system at their height of action. This is the method that was developed by Housner and is the method that was adopted by API 650 (Fig. 1). The method used in this analysis, however, is to apply the actual pressure distribution to the tank wall. To put the two different methods into mathematical terms, Housner's method applies the magnitude of the total hydrodynamic hoop pressures at the centroid of the pressure distribution. The pressure distributions can be described by the equations presented below

$p_{i}(z, \theta)=N_{i}(z) q_{o}(z) A_{i} \gamma_{w} G R \cos \theta \quad$ (high aspect ratio)

$p_{i}(z, \theta)=N_{i}(z) q_{o}^{\prime}(z) A_{i} \gamma_{w} G H \cos \theta \quad$ (low aspect ratio) 
$p_{c}(z, \theta)=N_{c}(z) q_{c}(z) A_{c} \gamma_{w} G R \cos \theta$.

These pressure distribution equations were taken from the New Zealand seismic document (NZSEE) [31] which are based on the Housner's method for rigid tanks as in API 650. Because API 650 does not provide explicit pressure distribution equations, the New Zealand seismic document's pressure distributions were used. Equations (1) and (2) are mathematically equivalent and can be used interchangeably (NZSEE) [31]. However, based on the tank geometry, it may be more intuitive to use Eq. (1) for high aspect ratios and Eq. (2) for low aspect ratios. In this context, a tank with a low aspect ratio is short and has a large radius while a tank with a high aspect ratio is tall and slender. The variables, $N_{i}(z)$ and $N_{c}(z)$, are dimensionless coefficients for the pressure distribution for the impulsive and convective modes taking into account the tank aspect ratio and the thickness of the shell. The parameters $H$ and $R$ are the tank liquid height and tank radius, respectively. The variables, $q_{0}(z)$ and $q_{0}^{\prime}(z)$, are the maximum pressures achieved at the base of the tank shell and are dimensionless; $q_{0}(z)$ is for tall tanks and $q_{0}^{\prime}(z)$ is for tanks with a large radius. However, it should be noted that the product of $q_{0}(z)$ and $R$ and the product of $q^{\prime}{ }_{o}(z)$ and $H$ are equivalent regardless of the tank geometry. The variable, $q_{c}(z)$, is dimensionless and represents the maximum convective force achieved at the top of the tank. The pairs, $\left(N_{i}(z) q_{o}(z)\right)$, $\left(N_{i}(z) q_{o}^{\prime}(z)\right)$ and $\left(N_{c}(z) q_{c}(z)\right)$ vary with liquid depth and were obtained for each of the tanks from "Appendix 1" section of the NZSEE document (NZSEE [31]. The variables $A_{i}$ and $A_{c}$ are the spectral response acceleration for impulsive and convective modes, respectively. The term $\gamma_{w} G$ is the specific weight of the stored liquid with $\gamma_{w}$ is the specific weight of water $\left(62.4\right.$ pcf or $\left.9.8 \mathrm{kN} / \mathrm{m}^{3}\right)$ and $G$ is the specific gravity of the stored liquid. The term $\cos (\theta)$ is used for the horizontal variation of the hydrodynamic pressure on the tank wall.

Now that the seismic demand has been fully defined, the pressure distributions can be applied to the tank. The

Table 5 Anchorage ratio, longitudinal stresses, allowable longitudinal stresses and uplift

\begin{tabular}{llllll}
\hline Tank ID & $\begin{array}{l}\text { Permis- } \\
\text { sible load } \\
\text { level (\%) }\end{array}$ & $\begin{array}{l}J \\
\text { (anchor- } \\
\text { age ratio) }\end{array}$ & $\begin{array}{l}\text { Longi- } \\
\text { tudinal } \\
\text { stresses } \\
\text { (ksi) }\end{array}$ & $\begin{array}{l}\text { Allowable } \\
\text { longi- } \\
\text { tudinal } \\
\text { stresses } \\
\text { (ksi) }\end{array}$ & \\
\hline 1 & 85 & 1.27 & 2.7 & 3.6 & 14 \\
2 & 45 & 1.30 & 4.5 & 5.0 & 14 \\
3 & 50 & 1.42 & 4.2 & 6.2 & 4 \\
4 & 30 & 1.39 & 5.3 & 6.2 & 4 \\
\hline
\end{tabular}

tanks were not designed to carry $100 \%$ of the seismic load as mentioned before. The permissible load levels are $85 \%$, $45 \%, 50 \%$ and $30 \%$ of the total seismic load based on API 650 design checks for tanks 1, 2, 3, and 4, respectively. The anchorage ratio, maximum longitudinal stresses, allowable longitudinal stresses and uplift are shown in Table 5 for each corresponding permissible seismic load level. However, in the FEA simulations we will apply the seismic loads up to $100 \%$ load level in order to see if the tanks are capable to carry the load without any failure and to investigate post buckling response at relatively high load levels. The next section will provide details as to how both the hydrostatic, gravity, and hydrodynamic loads were incorporated into the models.

\subsection{Finite element models}

The finite element models (FEMs) were created using Abaqus CAE 2016 [46]. As previously mentioned, the tanks comprised of nonlinear materials such that the elastic-plastic behavior of the tank under the seismic loads could be examined. The method from ASME Boiler and Pressure Vessels Code, Section VIII, Division 2 (ASME) [53] was used to obtain the "true" stress-strain behavior of the two materials which are presented in Fig. 4. It should be noted that the ASME method does not limit the amount of the strain that the material can reach. Therefore, the strain was limited to not exceed $20 \%$ in order to correspond to realistic strain levels. Nonlinear geometry deformations were included using the "Nlgeom" feature in Abaqus.

The tanks were constructed using bi-linear quadrilateral S4R elements. The tank shell courses vary in thickness. The middle surfaces of the shell courses were aligned in the models. This type of alignment is also relatively common in actual tank manufacturing practices, together

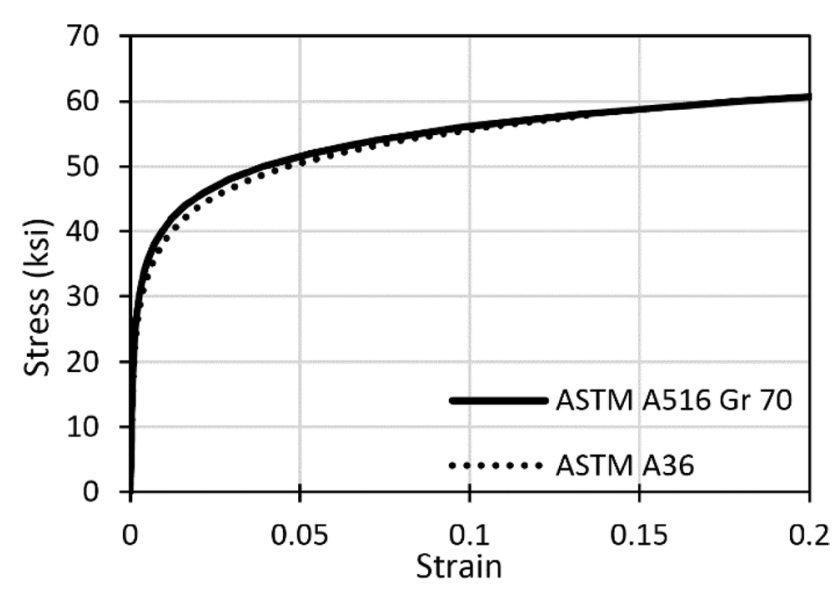

Fig. 4 "True" stress strain behavior for ASTM A516 Grade 70 steel and A36 steel using the ASME method 
with alignment of inner surfaces of the shells. Each tank had, on average, approximately 30,000 elements making up the tank shell, base, and wind girders. Quadratic elements (S8R) were deemed unnecessary due to the fact that a fine mesh design for the tanks was used and in order to reduce computing times. In addition, quadratic elements (S8R) were inconvenient to use for the tank base which was attached at the nodes to spring elements representing the soil foundation. The tributary area calculation to
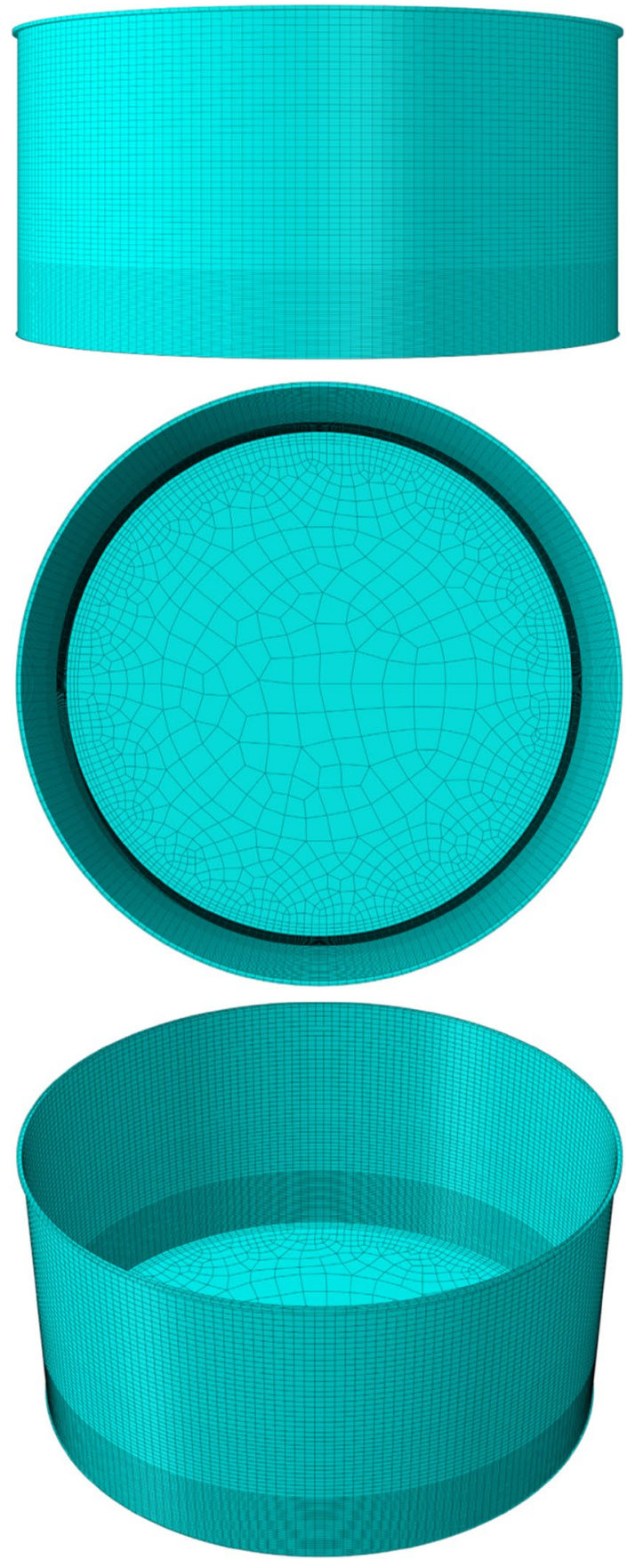

Fig. 5 Mesh design for Tank 1 convert soil subgrade modulus to an equivalent nodal spring stiffness would be rather cumbersome because of the mid-side nodes of a quadratic element (S8R) idealizing the tank base. The mesh was refined in areas where high deformations was anticipated, such as near the base-toshell connection; a coarser mesh was used away from this joint. The refined mesh size was obtained from conducting a mesh convergence study. An example of FEA mesh is shown in Fig. 5 for Tank 1; Tanks 2, 3 and 4 all had similar mesh designs. The tank shell, base, and wind girder thicknesses for each tank were used corresponding to their respective values in Tables 2 and 3 .

The loads applied to the tank were broken into two steps within Abaqus simulations. The first step, which uses a static (general) step, consists of only the hydrostatic load due to stored liquid and gravity load due to self-weight. The loads in the first step consist of the hydrostatic liquid pressure acting on the shell wall, the liquid bearing pressure on the tank base, and gravity which acts only on the tank structure (steel). The tanks were assumed to be completely full with liquid. The hydrostatic pressure was assumed to act over the entire height of the tank. The base pressure due to the bearing of the liquid on the base was equal to $15.6 \mathrm{psi}(108 \mathrm{kPa})$ and $21.84 \mathrm{psi}(151 \mathrm{kPa})$, respectively, for tanks with heights of $40 \mathrm{ft}(12.2 \mathrm{~m})$ and $56 \mathrm{ft}$ $(17.1 \mathrm{~m})$. The combination of these loads represents the state of the tank just before the seismic event.

The loads in the second step include the seismic forces. The loads from the first step are propagated to the second step such that the state of the tank at the beginning of the second step was identical to the state of the tank at the end of the first step; the loads from the first step did not change before or after moving from the first to second step. The second step uses Riks analysis [54], an arc-length method to solve nonlinear load-deformation equations, in order to determine the buckling shape and buckling load in which the seismic forces induce in the tank shell and base. Moreover, Riks analysis allows the buckling load and post buckling behavior to be accurately obtained by using small arc-length increments including both displacement and load. The seismic forces used in the second step consist of the hydrodynamic force pressure distributions that were defined with Eqs. (1) through (3). It should be noted that, realistically, the pressure due to the liquid acting on the tank base is not perfectly uniform during the seismic event due to the generated sloshing waves and the uplift in the tank base. However, the height of the sloshing waves that would be produced for this ground motion are relatively small, and magnitude of uplift at the tank base relative to its undeformed position are negligible in terms of the additional shell stresses achieved due to the repositioning of the liquid height contained in the shell. The maximum tank uplift values as shown in Table 5 

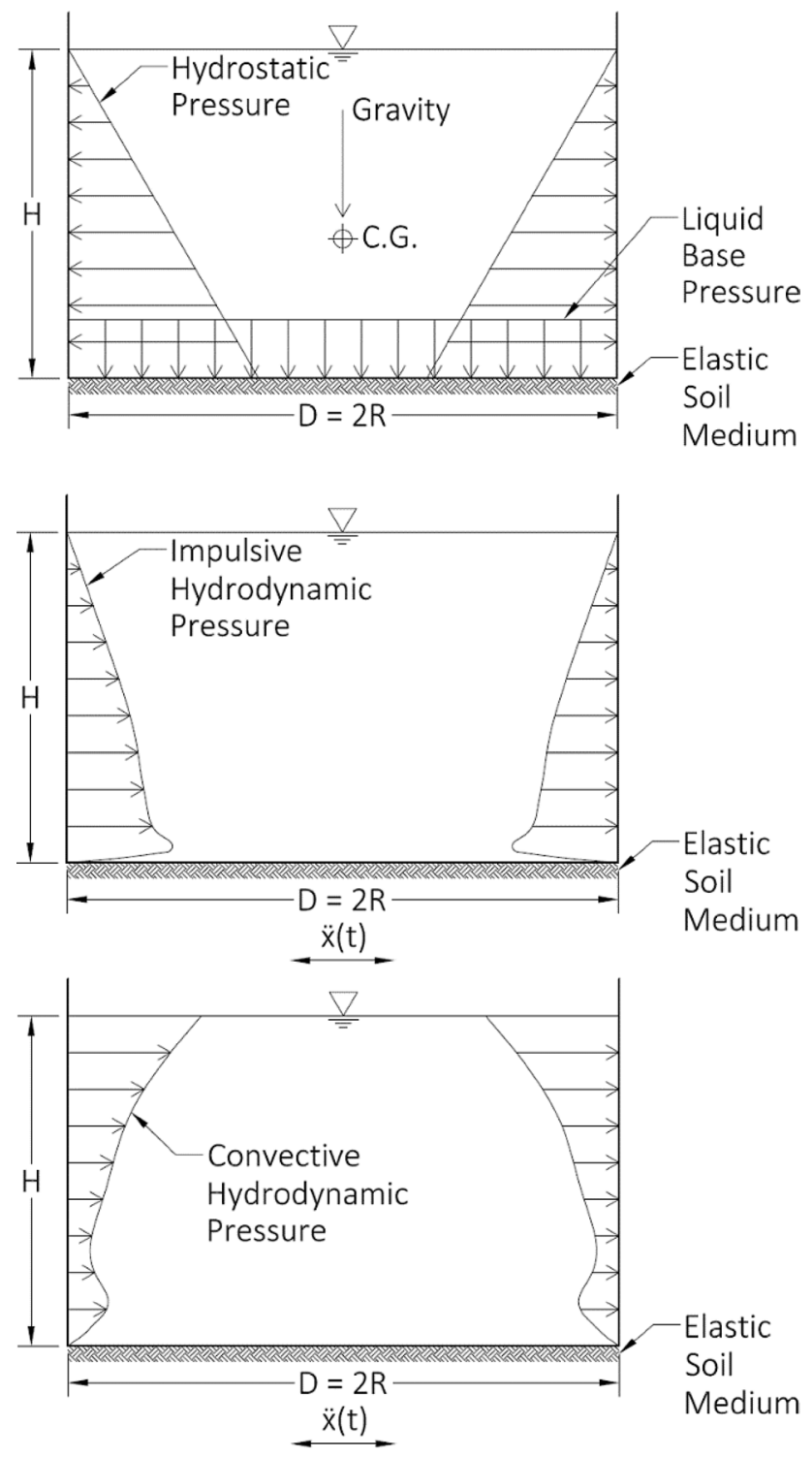

Fig. 6 Hydrostatic and hydrodynamic pressure distribution on tank

do not exceed 14 inches $(0.36 \mathrm{~m})$, which is less than $3 \%$ of the tank heights. Thus, these effects would not have a severe impact on the results and were ignored; the liquid pressure on the tank base was assumed to remain uniform during the seismic event. The hydrostatic and hydrodynamic loads applied to the model and they are shown in the Fig. 6.

Before running the analysis with the imperfections, a verification of the models was made to ensure the procedures, and in particular, the seismic loads used were adequate for this study. To do so, each of the tanks was analyzed for full hydrodynamic loads for rigid base conditions. Nonlinear material and geometry deformation properties were used despite not being included in the API 650 Annex E provisions or the theoretical equations developed by Housner. The impulsive and convective forces were applied to the tank separately in order to determine their resulting shell stresses. The stresses reached in each shell course were then compared to the respective API 650 hoop stress provisions and the theoretical equations developed by Housner (which the API 650 equations are based on). The equations for estimating the hoop stress in a given shell are given in "Appendix 1" section for US customary units and "Appendix 2" section for SI units. For each of the tanks, the FEM stresses for the convective and impulsive modes for each shell course were within $10 \%$ of the theoretical stresses from API 650 . Moreover, a study completed by Taniguchi et al. [55] showed that the pressure distributions used in this study compared quite well to FEA of storage tanks under seismic loads using a fluid-structure interaction and time-history approach. Therefore, it was concluded that the seismic force distributions and mesh design were satisfactory.

Three different scenarios were considered in this analysis concerning imperfections and include tanks with OOP imperfections only, tanks with OOR imperfections only, and tanks with OOP and OOR imperfections combined.

The tanks that had OOP imperfections were constructed in Abaqus to have the desired level of "plumb." According to Section 7.5 of API 650, which addressed the dimensional tolerances during constructions, the maximum out-of-plumbness in the tank of the top with respect to the shell-to-base connection is $0.5 \%$ of the tank height $(\mathrm{H} / 200)$. Therefore, a horizontal displacement at the top of the tank of 2.4 in. $(6.1 \mathrm{~cm})$ and $3.36 \mathrm{in} .(8.5 \mathrm{~cm})$ for tanks with a height of $40 \mathrm{ft}(12.2 \mathrm{~m})$ and $56 \mathrm{ft}(17.1 \mathrm{~m})$, respectively, were built into the tank. It should be noted that the seismic loads were applied to the tank in the direction that the tank was tilted. For example, the tanks were oriented such that the tilt was in the positive $x$-direction. The seismic forces were also assumed to act concurrently with the tilt in the positive $x$-direction. Literature suggests that applying loads in the same direction of the tilt provides the most significant impact to the load-carrying capacity of the tank [41-43].

For tanks that included OOR imperfections, the same Riks analysis previously mentioned was employed. The hydrostatic, hydrodynamic, and gravity loads were applied to the tank to identify the significant buckling mode and shape using a linear perturbation step in Abaqus. The eigenmode that most exhibited the expected failure in the tank under the seismic loads, namely, the elephant's foot buckle near the base-to-shell connection, was selected as the eigenmode. Several other significant mode shapes could have been used for the OOR imperfections, but the most critical mode is one that induces an elephant foot buckle at the base connection prior to the seismic load being applied to the tank. The tank in the final spring 
configuration was used to determine the OOR imperfection, which would allow the uplifting of the tank during the buckling failure.

The tanks were assumed to be supported by a series of elastic springs with a spring stiffness equivalent to the soil stiffness of a Class D soil. The FEMA-1050 document [56] was used to correlate the properties of a Class D soil to an estimate of the vertical modulus of subgrade reaction (MSGR). The resulting MSGR was determined to be approximately $100 \mathrm{lb}$ per square inch per inch (psi/ inch) $(21.7 \mathrm{MPa} / \mathrm{m})$. The spring stiffness for each base node was then obtained by multiplying the tributary area of each base node by the MSGR. Due to the nature of the base mesh, the spring stiffness was different for each node. Once the spring stiffness for each node was determined, the loads could be applied to the tank. One issue with the spring elements (SPRING1) in Abaqus is that they provide stiffness in both tension and compression. However, the stiffness of a soil in tension is almost nearly zero. Therefore, the springs that were in tension due to the uplifting side of the tank must be removed. This was achieved by applying the loads in the second step (seismic forces) in increments of $25 \%$ of the total seismic force. For example, in the first iteration, the tank was loaded to $25 \%$ of the total seismic forces to determine springs in tension. The springs that were in tension were then removed, and the seismic load was increased to $50 \%$. This would continue until the tank was in equilibrium with no springs in tension. Once the tension springs had been identified and removed, the final spring configuration was determined, and the analysis for finding the buckling modes shapes was conducted. For capturing the tank uplift springs were used rather than computationally expensive contact algorithm, so that the analysis was computationally less expensive. Furthermore, for the given problem the spring algorithm is able to capture the behavior of the tank uplift.

The OOR imperfections use the final spring layout with no springs in tension. $100 \%$ of the seismic forces and $100 \%$ of the hydrostatic and gravity forces were used to determine the mode shapes for Tank 1. For Tanks 2, 3 and 4, however, the load to cause buckling occurred well before $100 \%$ of the seismic forces. Therefore, the buckling mode shape for Tanks 2, 3, and 4 were determined for $70 \%, 60 \%$, and $40 \%$ of the seismic forces and $100 \%$ of the hydrostatic and gravity forces, respectively. The failures of each of the tanks will be discussed in more detail in the proceeding section; this section avoids a discussion of the failure of the tank for clarity. Due to the limited data on the value of the imperfection amplitude for OOR imperfections, the limits for construction dimension tolerances were used. According to API 650 Section 7.5, the allowable deviation in the shell radii is $0.75 \mathrm{in} .(19 \mathrm{~mm})$ and $1.25 \mathrm{in} .(32 \mathrm{~mm})$ for tanks with diameters of $40 \mathrm{ft}(12.2 \mathrm{~m})$ and $80 \mathrm{ft}(24.4 \mathrm{~m})$, respectively. Therefore, the buckling shape determined for each tank from the bifurcation analysis was scaled to achieve a maximum OOR corresponding to these tolerances based on their geometry. Rotter [41] has also suggested an OOR imperfection amplitude according to the following equation which was also investigated for each of the tanks

$\frac{\delta}{t}=\frac{0.06}{a} \sqrt{\frac{R}{t}}$

where in Eq. (4), which is must be dimensionally consistent, $\delta$ is the magnitude of the imperfection in inches $(\mathrm{mm})$, $t$ is the thickness of the bottom shell course in inches $(\mathrm{mm}), \mathrm{R}$ is the tank radius in inches $(\mathrm{mm})$, and $\mathrm{a}$ is the construction quality factor. The construction quality factor is specified to be 1.0 for "normal construction," 1.5 for "quality construction," and 2.5 for "very high quality construction."The most critical case is thus for an assumed "normal" construction quality which was investigated in this report. The corresponding imperfection results in magnitudes for

\section{No OOP imperfection}

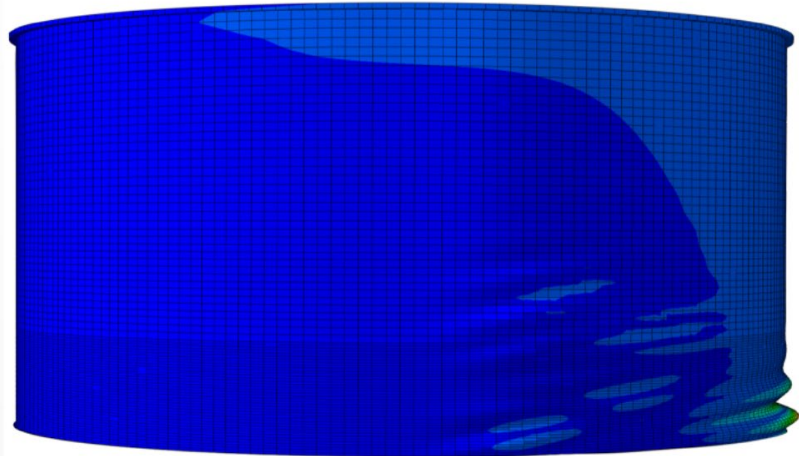

With OOP imperfection $=2.4$ inches

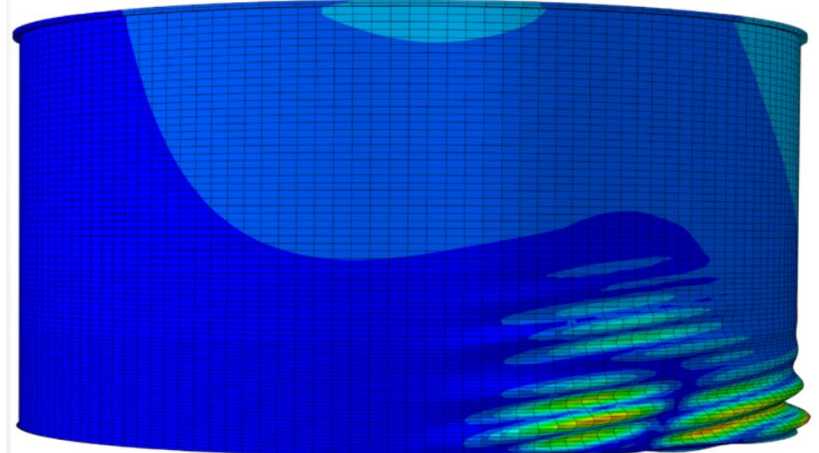

Fig. 7 Buckled mode shape to be used for OOR imperfections for Tank 1 with and without OOP imperfections magnified 20 times 
Tanks 1 through 4, respectively, of $0.71 \mathrm{in.}(18 \mathrm{~mm}), 0.84 \mathrm{in}$. $(21 \mathrm{~mm}), 0.46 \mathrm{in} .(12 \mathrm{~mm})$, and $0.46 \mathrm{in} .(12 \mathrm{~mm})$. Note that Rotter's approach on OOR imperfection was adopted by New Zealand standard and European Standard as well.

For tanks with OOR and OOP imperfections, the same procedure described above was used for determining the spring layout for the tank with the OOR imperfection. The OOP buckling mode shape would then be determined based on the spring configuration for the tank with the OOR imperfection. In all cases, the spring layouts between the perfect tanks and the tanks with the OOR imperfections were nearly identical. Figure 7 shows the mode shape, which is magnified by 20 times, for Tank 1 determined using the bifurcation procedure for the conditions with just the OOR imperfections and for the combined OOR and OOP condition.

\section{Results}

This section discusses the behavior of the tanks under seismic loads using the FEMs described in Sect. 2 . The discussion is broken into four parts to provide a clear layout of the procedures used to conduct the analysis. The first section consists of the behavior of the tanks without imperfections and the global failure phenomena observed. The second and third sections describe the failure of the tanks with the OOR and OOP imperfections. The final section combines the OOR and OOP imperfections. The tanks without imperfections are used as benchmarks to compare to the tanks with OOR and OOP imperfections. The failure mechanisms observed for each of the conditions without imperfections are also examined.

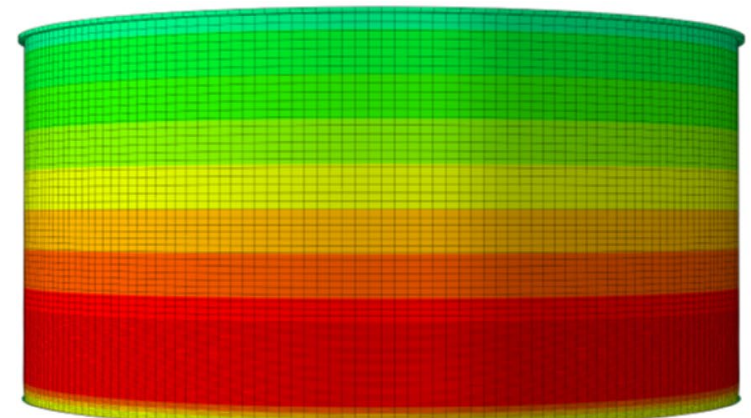

(a) $0 \%$

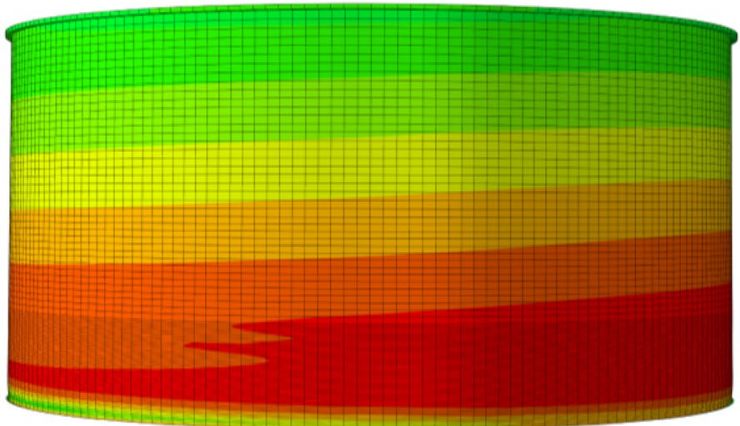

(b) $25 \%$

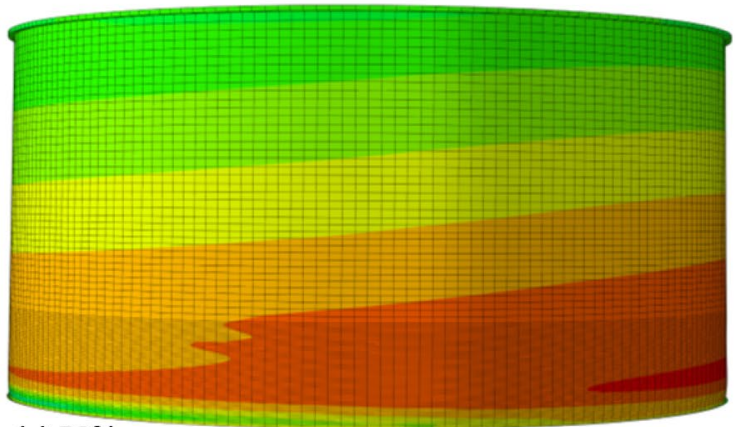

(c) $50 \%$

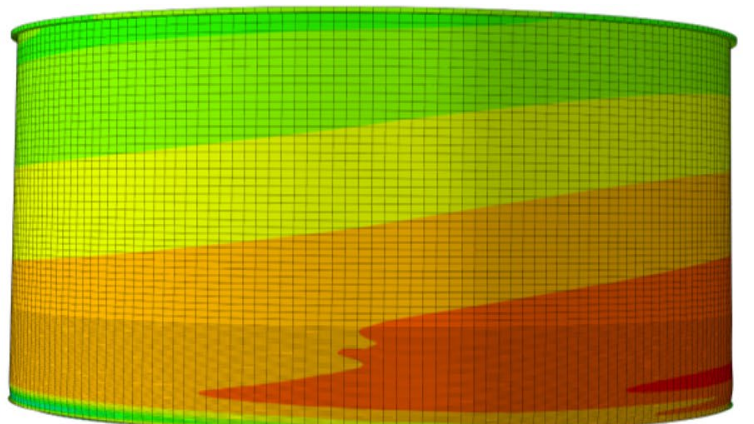

(d) $75 \%$

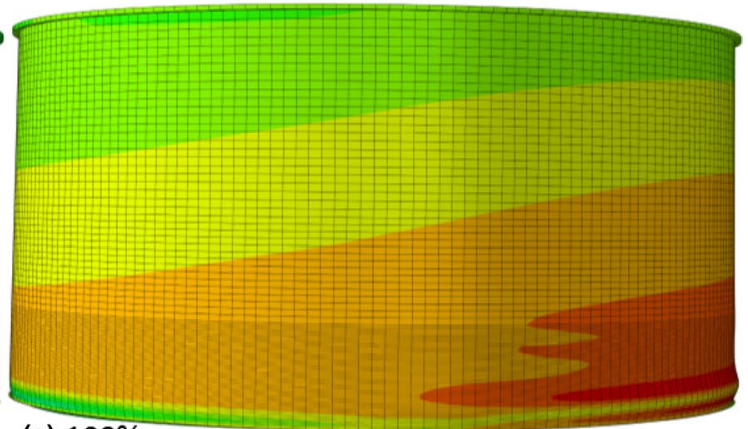

(e) $100 \%$

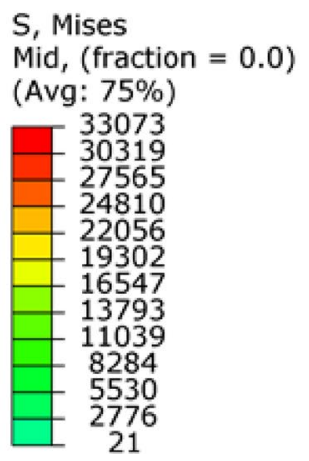

Fig. 8 Global failure of Tank 1 for $25 \%$ seismic load increments with no imperfections. Mid-surface von Mises stresses are plotted. Legend shows the stresses in psi for the last step ( $100 \%$ of the load) of the analysis 


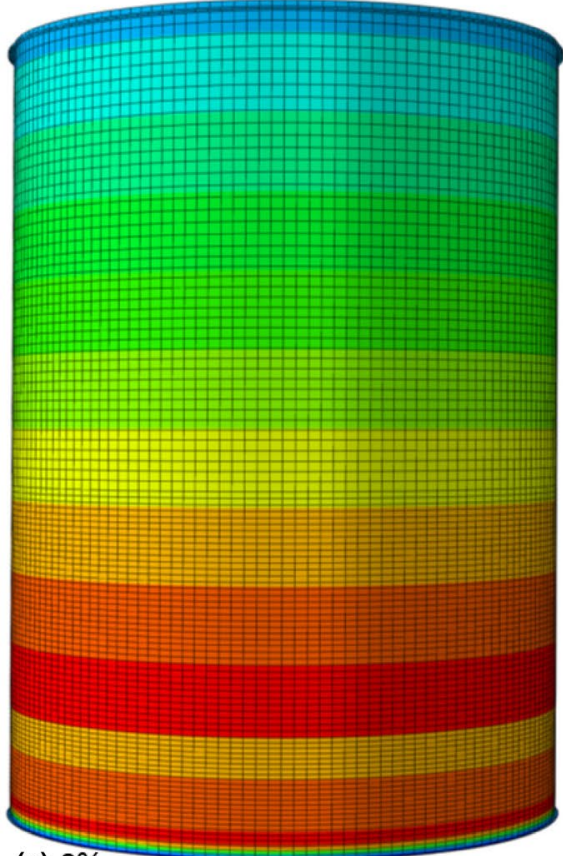

(a) $0 \%$

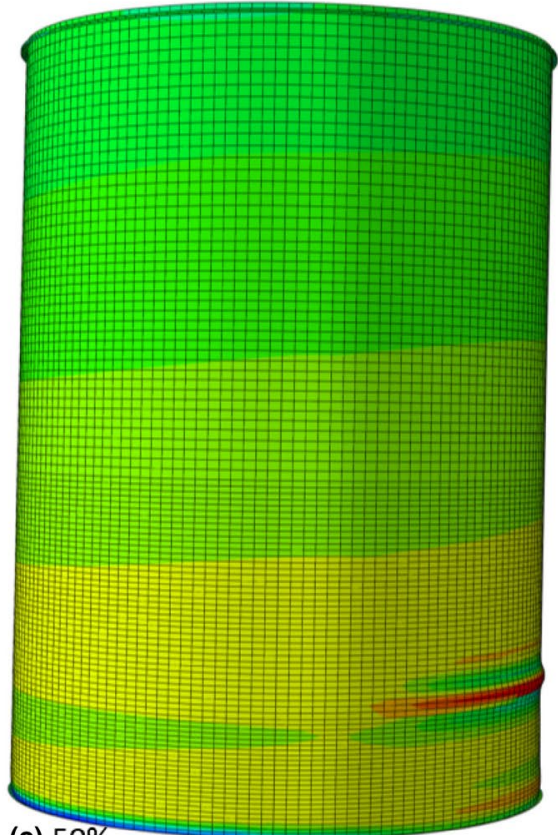

(c) $50 \%$

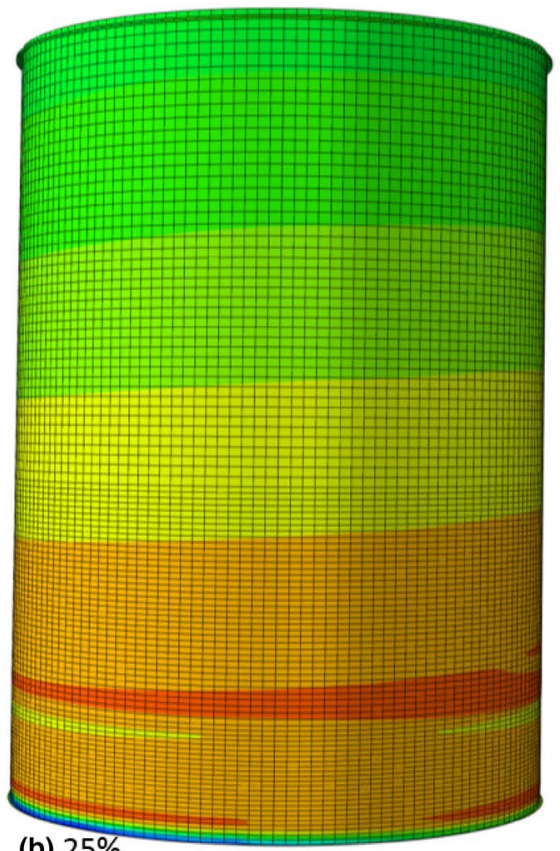

(b) $25 \%$

\section{S, Mises}

Mid, $($ fraction $=0.0$

(Avg: $75 \%$ )

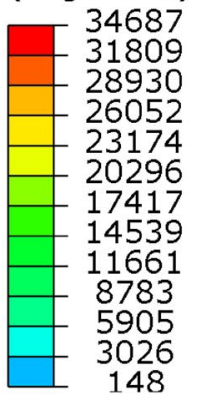

Fig. 9 Global failure of Tank 4 for $25 \%$ seismic load increments with no imperfections. Mid-surface von Mises stresses are plotted. Legend shows the stresses in psi for the last step ( $50 \%$ of the load) of the analysis

\subsection{Global failure}

The tanks experienced a global stability failure as the seismic forces were increased for the conditions of geometrically perfect tanks and the conditions for the tanks with imperfections. The global failure mechanism observed for each of the tank failures was elephant's foot buckling.
The elephant's foot buckling is global failure because the radial deflection is larger than the tolerable value of $0.05 R$ or 20t as indicated by EN 1993-4-1 [57]. The elephant's foot buckle occurred either near the base-to-shell connection or at the abrupt change in shell thickness for the tanks which used a base shell thickness of $0.25 \mathrm{in} .(6 \mathrm{~mm})$. Note that the base shell thickness of $0.25 \mathrm{in} .(6 \mathrm{~mm})$ is 
the minimum base shell thickness prescribed by API 650 . Figures 8 and 9 are provided to better visualize how the elephant's foot buckle developed as the seismic forces were increased for Tanks 1 and 4, respectively. Note that diamond-shaped buckling was not observed in any of the tank models under consideration. This result was somewhat expected because diamond-shaped buckling typically happens in very thin shells such as stainless steel wine storage tanks (NZSEE) [31].

Figures 8 and 9 show the global failure (elephant's foot buckling) for Tanks 1 and 4; the stress contours are for von Mises membrane stresses and are provided only for reference of where stress concentrations appear throughout the analysis. Therefore, in Figs. 8 and 9, stress legends are only provided corresponding to the last step of the analysis. It is apparent that at the initial stage at the end of the first step, which includes only the hydrostatic and gravity forces acting on the tank, the stress begins to build up on the side of the tank in which the seismic forces are acting (positive $x$-direction). On the opposite side, the tank base begins to uplift from the foundation. Another interesting observation is that for both tanks there are distinct increases in shell stress at the location of shell course junctions where the maximum stress in a given shell course is located at the junction. This is expected as the shell thicknesses decrease between shell courses the shell stresses will increase. Moreover, the maximum shell stress in a given shell course is expected at the bottom of the course due to the increase in the hydrostatic and impulsive hydrodynamic pressure distributions increase with increasing liquid depth.

The load-deformation response of each of the tanks without imperfections is presented in Fig. 10. The vertical axis in Fig. 10 represents the amount of seismic force being applied to the tank walls. Note that the hydrostatic and gravity loads are also applied in the first step, but are not increased by any amount with the increase of seismic

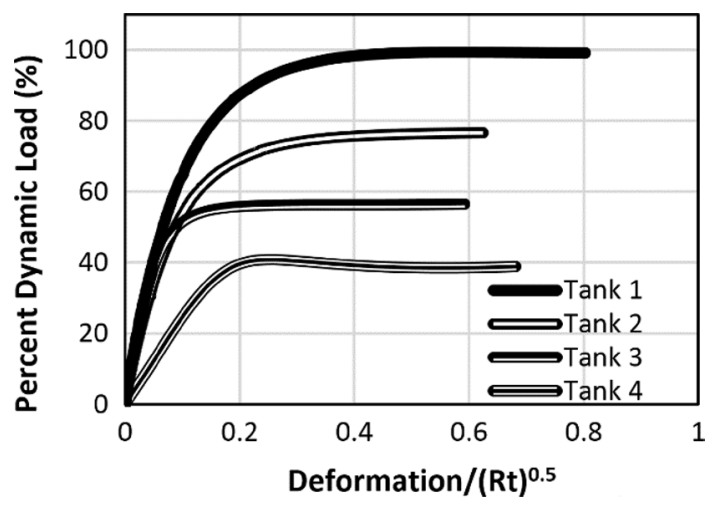

Fig. 10 Load-deformation curves for each of the tanks with no imperfections force. The horizontal axis represents the deformation in the $x$-direction of the tank (the direction the loads are applied) at the node that experiences the most deformation in the $x$-direction. For a given tank, the same node is used to read deformation values for different load levels. The deformations have been normalized by a factor of $(\mathrm{Rt})^{0.5}$, where $\mathrm{R}$ is the tank radius and $t$ is the thickness of the bottom shell course, for convenience in order to eliminate any unit conversions. The failure level is defined as the point at which the tank can no longer dissipate the seismic forces without undergoing substantial deformations. The deformations exhibited were in the form of the elephant's foot buckling at the shell base (Figs. 8, 9), and the point at which the buckle starts to develop in the tank shell corresponds to the plateau in Fig. 10. There is an apparent trend between the aspect ratio $(H / R)$ and the tank failure, whereas the aspect ratio decreases, the seismic forces required to cause the onset of failure increases. Moreover, the level of failure that is achieved in the tank under the seismic loads can be correlated quite well to the overturning stability ratio, called the anchorage ratio, J, prescribed by API 650. It was shown in a companion paper that the amount of seismic force to induce failure in the tank was nearly equivalent the force at which API 650 estimated the tank system would become unstable [28]. However, in order to avoid further discussion of this rather lengthy conclusion, the readers are referred to the companion paper [28]. The load-deformation responses presented for each of the perfect tanks are used for the comparative response of the tanks with imperfections in the proceeding sections.

\subsection{Out-of-plumbness imperfections}

The out-of-plumbness (OOP) of a tank is the amount of relative displacement of the top of the shell with respect to the shell-to-base connection. Tanks 1 and 3 had a total OOP tilt of 2.4 in. $(6.1 \mathrm{~cm})$ and Tanks 2 and 4 had a total OOP tilt of $3.36 \mathrm{in} .(8.5 \mathrm{~cm})$. As previously discussed, the OOP imperfection magnitudes were determined using the API 650 dimensional construction tolerances, which is prescribed as $0.5 \%$ of the tank height. Therefore, the corresponding OOP imperfection magnitude as a percentage of the tank radius are $0.5 \%, 0.7 \%, 1.0 \%$, and $1.4 \%$, respectively.

Figure 11 shows OOP load-deformation curves for each of the tanks compared to the perfect tank configuration. The behavior of each tank with the OOP imperfections were not identical, therefore, the axes minimum and maximum values for the percent dynamic load and arc length were changed for each tank to better show the distinction between the perfect tank and imperfection tank responses in Fig. 11. Tanks 1, 2, and 3 all reached a maximum dynamic 

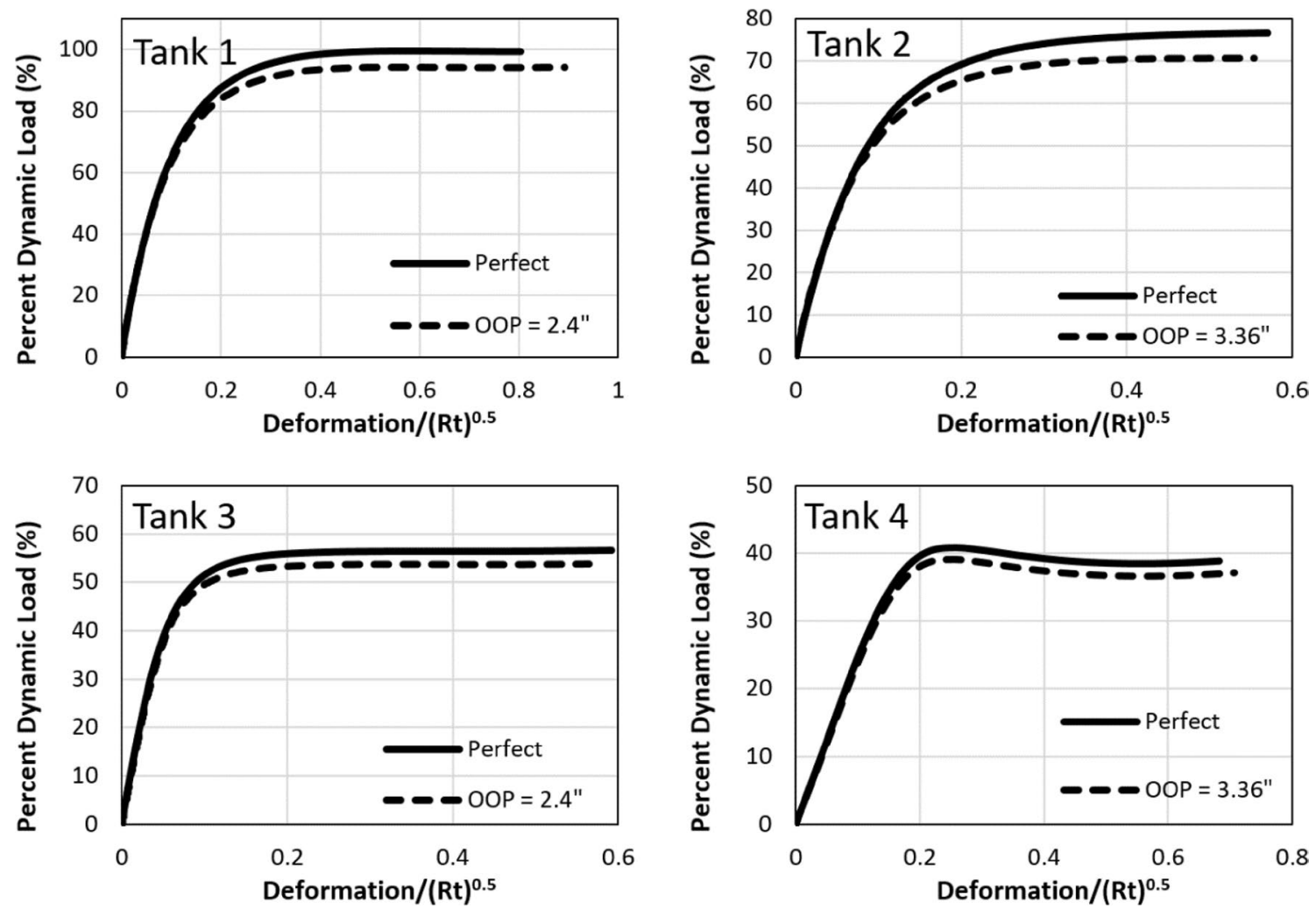

Fig. 11 Load-deformation curves for each tank with OOP imperfections and their respective perfect tank response

Table 6 Maximum seismic load-carrying capacity for perfect tanks and tanks with out-of-plumbness imperfections

\begin{tabular}{lllll}
\hline Tank ID & $\begin{array}{l}\text { Perfect tank } \\
(\%)\end{array}$ & $\begin{array}{l}\text { OOP imperfec- } \\
\text { tion (\%) }\end{array}$ & $\begin{array}{l}\text { Difference } \\
(\%)^{\mathrm{a}}\end{array}$ & Ratio $^{\mathrm{b}}$ \\
\hline 1 & 100 & 94 & 6 & 0.94 \\
2 & 77 & 71 & 6 & 0.92 \\
3 & 57 & 54 & 3 & 0.95 \\
4 & 41 & 39 & 2 & 0.95 \\
\hline
\end{tabular}

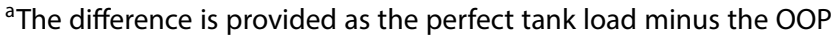
imperfection tank load

${ }^{\mathrm{b}}$ The ratio is provided as the OOP imperfection load divided by the perfect tank load

load at which point no more load could be applied without resulting in large deformations-this is characterized by the distinct "plateau." Tank 4, on the other hand, reached a distinct maximum value for the applied dynamic load, which was quickly followed by a drop in the applied load to cause large deformations in the tank. This observed behavior for Tank 4 was consistent between the perfect and imperfect tank for each of the tanks. Therefore, the difference in behavior between Tanks 1, 2 and 3 and Tank 4 could be attributed to the fact that Tank 4 has the highest aspect ratio of 2.8 , indicating that Tank 4 is largely unstable for the given dynamic loading.

The maximum dynamic load achieved at failure for each of the tanks are shown in Table 6 . The values are presented as a percentage of the seismic load applied to the tank. The difference between the perfect tank and tank with the OOP imperfection are also provided. The amount of reduction in the buckling strength of the shell is commonly referred to as the knock-down factor, which is the ratio of the stress reached in the imperfect shell to the buckling stress to cause failure in the perfect tank, and is also provided in Table 6.

For each tank, it is apparent that the OOP imperfection caused a slight drop in the seismic load to cause failure. The largest total drop in load was for Tank 1 at 6\%; the smallest knock-down factor was 0.92 for Tank 2. Moreover, there seems to be no correlation between the amount of OOP deformation as a fraction of the tank radius and the amount of reduction in seismic loadcarrying capacity. For example, Tank 4 had the largest tilt with respect to the tank radius at $1.4 \%$, but had the largest knock-down factor. Tank 3, however, had the second smallest tilt with respect to the radius at $0.7 \%$, but had the smallest knock-down factor. The difference in the theoretical hoop stress equations and the FEM stress 
results for the impulsive and convective pressure distributions observed during model verification were on the order of $10 \%$. Thus, a difference in the maximum seismic loads achieved in the perfect tanks and OOP tanks that is less than the margin in error of the FEMs alone is rather insignificant. It can be therefore concluded that, for the tanks assessed in this study, the OOP imperfection alone does not pose a significant risk to the tank during a seismic event.

\subsection{Out-of-roundness imperfections}

Out-of-roundness is an imperfection that occurs within a given shell course and is a displacement of the shell with respect to the undeformed configuration. As previously mentioned, the amplitude of the OOR imperfection permitted by API 650 during construction is $1.25 \mathrm{in}$. (32 mm) for Tanks 1 and 2 and 0.75 in. (19 mm) for Tanks 3 and 4. Moreover, Rotter [41] developed a simple expression to account for OOR imperfections in the tank shell based on the quality of construction. The OOR imperfection amplitudes for Tanks 1 through 4, respectively, assuming a normal construction quality, were determined to be $0.71 \mathrm{in}$. $(18 \mathrm{~mm}), 0.84$ in. $(21 \mathrm{~mm}), 0.46 \mathrm{in.}(12 \mathrm{~mm})$, and $0.46 \mathrm{in}$. $(12 \mathrm{~mm})$. Therefore, each of the tanks was assessed for two magnitudes of OOR imperfections corresponding to the API 650 provisions and the NZSEE recommendations for normal construction. Note that it is possible to have a higher quality construction with more stringent OOR imperfection tolerances for tanks designed according to the NZSEE document.

Figure 12 shows the load-deformation curves for each of the tanks with the API 650 and NZSEE imperfection levels and their corresponding perfect tank responses. The node with maximum hoop stress at the initiation of buckling was selected for plotting the load-deformation curves. Each of the tanks appears to undergo responses due to the OOR imperfections in quite different manners. The imperfections induced in Tanks 1 and 2 slightly reduced the load-carrying capacity compared to the perfect tank. The load-deformation behavior of Tanks 1 and 2, as the seismic loads are applied, with and without imperfections tends to be the same-the maximum load is achieved in the shell followed by a plateau of large deformations. Tank 3, to much surprise, was able to reach a higher seismic load by inducing the OOR imperfection into the tank compared to the perfect tank. It should be noted that the maximum failure load achieved in Tank 3 occurs at a much higher deformation compared to the perfect tank condition. However, the increase in strength of Tank
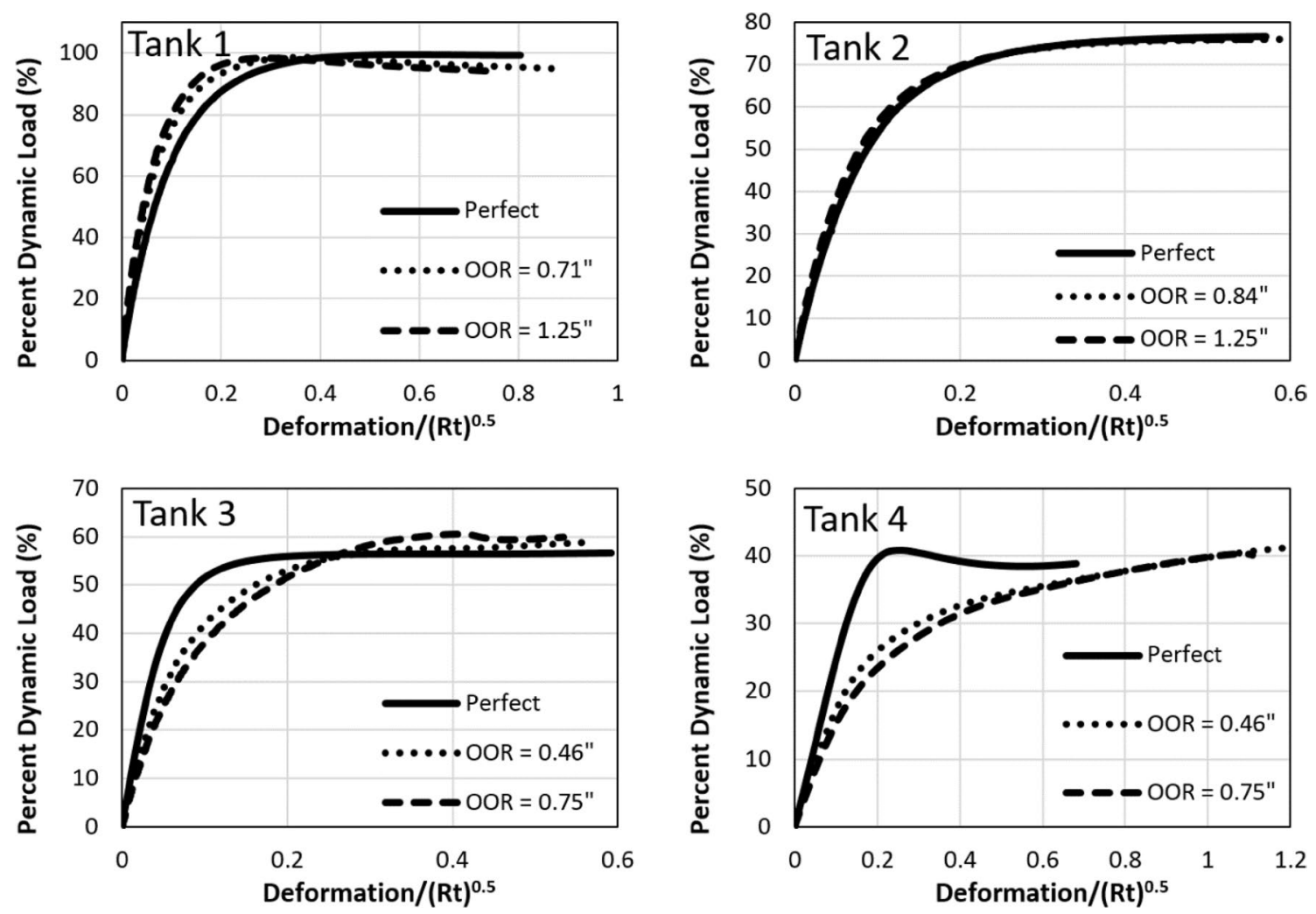

Fig. 12 Load-deformation curves for each tank with OOR imperfections and their respective perfect tank response 
3 could be attributed to the fact that the location of the imperfection and the location of the elephant's foot buckling may not perfectly align with each other. Therefore, the imperfection could potentially help to strength the area around the elephant's foot buckle that develops as the seismic forces are applied to the tank. Tank 4 reaches a distinct maximum load point for the perfect tank. However, by incorporating the imperfections, this distinct point is removed, and the tanks with imperfections appear to undergo a more prolonged failure. Thus, it appears that Tanks 3 and 4 undergo a softening effect in the steel due to the OOR imperfections where two to five times more deformation is required to reach the maximum failure load compared to their respective perfect tank conditions.

One common characteristic amongst each of the tanks is that the selected two imperfection amplitude levels appeared to have little effect on the response of the tank. In other words, the API 650 and NZSEE imperfection amplitudes produced essentially the same response in the tank despite the API 650 amplitudes being almost double that of the NZSEE amplitudes.

Table 7 shows the magnitudes of the maximum loads achieved in the shell at the instance of failure for each of the tanks with the API 650 and NZSEE imperfection amplitudes. Tanks 1 and 4 both had a knock-down factor of 0.98 , while Tank 2 had a knock-down factor of 0.99. Tank 3 had an increase in strength with knock-down factors of 1.07 and 1.04 for the API 650 and NZSEE provisions, respectively. Therefore, it appears that the introduction of the OOR imperfections in the shell of the tanks results in a random behavior. Moreover, for the tanks that did experience a reduction in the load-carrying capacity under the seismic loads with the OOR imperfections, the reduction in the capacity was only on the order of $1-2 \%$. Thus, it can again be concluded that the tanks OOR imperfections using the API 650 imperfection amplitudes do not significantly affect the behavior of the tanks under seismic loads. The NZSEE recommendation for OOR imperfection amplitude also appears to be satisfactory despite having a smaller magnitude for each of the tanks.

Table 7 Maximum seismic load-carrying capacity for perfect tanks and tanks with out-of-roundness imperfections

\begin{tabular}{llllll}
\hline Tank ID & $\begin{array}{l}\text { Perfect } \\
\text { tank } \\
(\%)\end{array}$ & $\begin{array}{l}\text { OOR imperfec- } \\
\text { tion-API 650 } \\
(\%)\end{array}$ & Ratio $^{\text {a }}$ & $\begin{array}{l}\text { OOR imperfec- } \\
\text { tion-NZSEE } \\
(\%)\end{array}$ & Ratio $^{a}$ \\
\hline 1 & 100 & 98 & 0.98 & 98 & 0.98 \\
2 & 77 & 76 & 0.99 & 76 & 0.99 \\
3 & 57 & 61 & 1.07 & 59 & 1.04 \\
4 & 41 & 40 & 0.98 & 40 & 0.98 \\
\hline
\end{tabular}

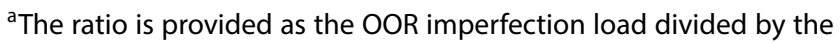
perfect tank load

\subsection{Combination of out-of-plumbness and out-of-roundness imperfections}

As a worst case scenario, the OOP and OOR imperfections were implemented into the models simultaneously. The OOP displacements were identical to those used in Sect. 3.2 for each respective tank. The OOR imperfection amplitudes were also the same as that for Sect. 3.3; both the API 650 construction tolerances and the NZSEE imperfection amplitude recommendation were used. The OOP and OOR were both oriented in the positive $\mathrm{x}$-direction of the tank, which is the direction that the seismic forces were acting on the shell wall. It should be noted that the probability of the seismic forces acting on the tank in the exact direction of the OOP imperfection or the OOR imperfection is quite unlikely. Thus, the probability of the seismic forces acting in the direction of the OOP and OOR imperfections concurrently is low, but still could occur. Although, this section presents an unlikely scenario in real-life seismic event, it can be viewed as a lower bound solution in terms of seismic capacity.

Figure 13 shows the load-deformations curves for each of the tanks with both the OOP and OOR imperfections. Each of the tanks except for Tank 1 had experienced a drop in the maximum dynamic load that the tank could dissipate before undergoing excessive deformations. Tanks 1 and 2 had the same response between the perfect tank and tank with the OOP and OOR imperfections in terms of load-deformation. Tanks 3 and 4 observed, again, the prolonged failure and softening effect due to the combination of the OOP and OOR imperfections. Tank 4 has a distinct peak dynamic load for the perfect tank condition but has a more prolonged failure with the combined OOP and OOR imperfections. This same response for Tank 4 was observed for both the OOP and OOR imperfections as was observed for the tanks with just the OOR imperfections (Sect. 3.3). Therefore, it is apparent that the OOR imperfections only are more influential in the tank response than the OOP imperfections. The results from Fig. 13 are quantified in Table 8.

The maximum reduction in load-carrying capacity was observed in Tank 4 with a knock-down factor of 0.93 . Tanks 2, 3, and 4 all observed a reduction in capacity on average of $5 \%$ with respect to the perfect tanks. Tank 1 appears to be an outlier as the imperfect tanks outperformed the perfect tank condition. As was concluded for tanks with OOR imperfections only, there is little difference between the tanks with amplitudes conforming the API 650 construction tolerances and the NZSEE amplitude recommendations. Thus, it appears that a small decrease in the performance of the tank with both OOP and OOR imperfections can be expected for tanks 

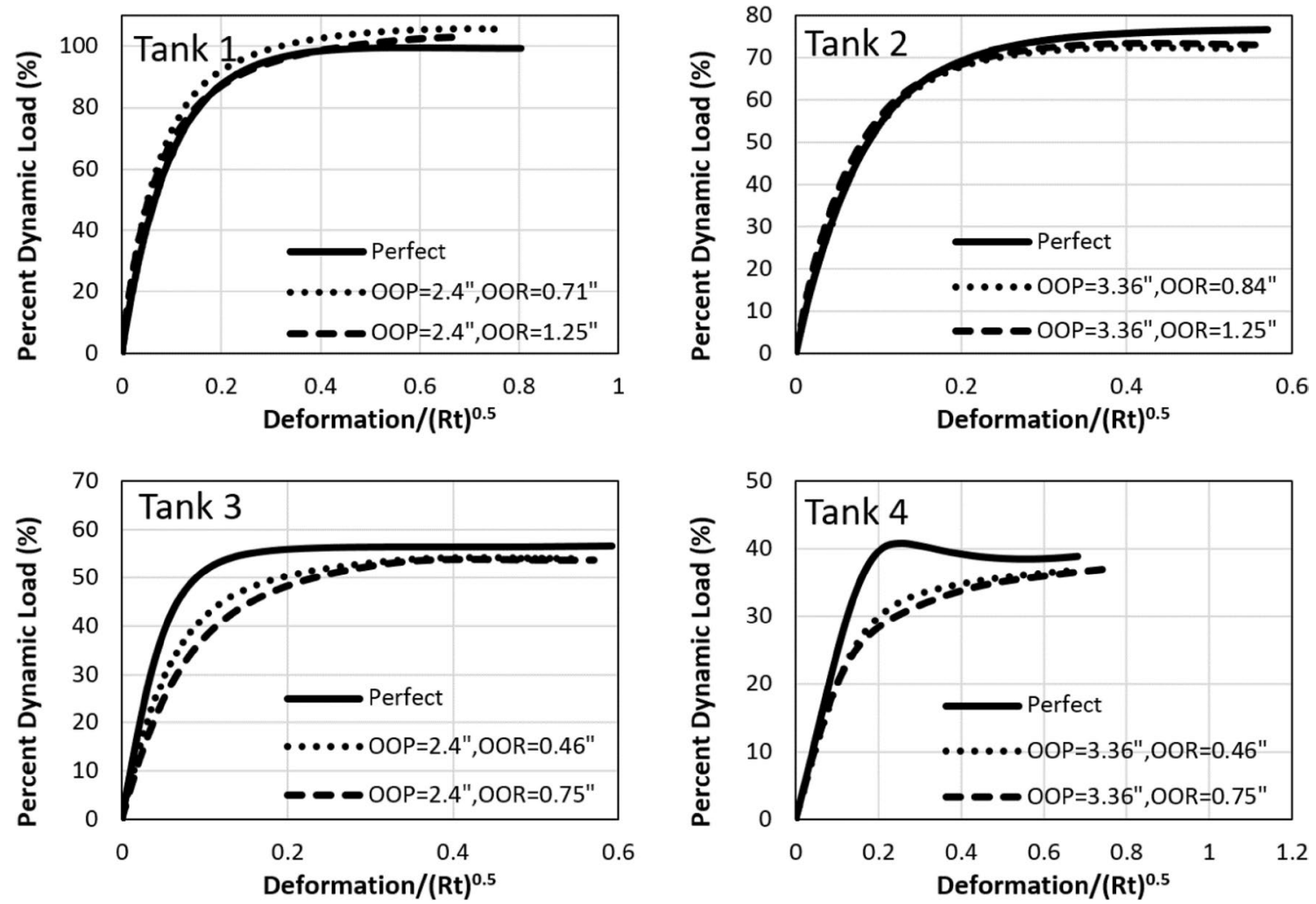

Fig. 13 Load-deformation curves for each tank with OOP and OOR imperfections simultaneously in the direction of the seismic load

Table 8 Maximum seismic load-carrying capacity for perfect tanks and tanks with out-of-plumbness and out-ofroundness imperfections

\begin{tabular}{llllll}
\hline Tank ID & $\begin{array}{l}\text { Perfect tank } \\
(\%)\end{array}$ & $\begin{array}{l}\text { OOP and OOR imperfec- } \\
\text { tions-API 650 (\%) }\end{array}$ & Ratio $^{\mathrm{a}}$ & $\begin{array}{l}\text { OOP and OOR imperfec- } \\
\text { tions-NZSEE (\%) }\end{array}$ & Ratio $^{\text {a }}$ \\
\hline 1 & 100 & 103 & 1.03 & 106 & 1.06 \\
2 & 77 & 74 & 0.96 & 72 & 0.94 \\
3 & 57 & 54 & 0.95 & 54 & 0.95 \\
4 & 41 & 38 & 0.93 & 39 & 0.95 \\
\hline
\end{tabular}

${ }^{\text {a }}$ The ratio is provided as the OOP and OOR imperfection load divided by the perfect tank load with small OOR imperfection amplitudes (less than 1.25 in, $32 \mathrm{~mm}$ ). However, the decrease in the load-carrying capacity is quite negligible considering the expected error in the FEMs, and therefore, imperfections in general a not a critical factor to be considered for uplifting tanks experiencing seismic forces.

\section{Conclusion}

Several unanchored aboveground, steel, welded, opentop, flat-bottom, liquid-containing, storage tanks with geometric imperfections subjected to seismic forces were analyzed using Abaqus CAE 2016. The tanks had nonlinear materials, nonlinear geometry deformation properties, and a flexible soil foundation simulated by a series of elastic springs corresponding to a Class D soil. Two imperfection types were used. The first imperfection introduced into the tanks is the relative initial displacement of the top of the tank shell with respect to the shell-to-base connection and is referred to as an out-of-plumbness (OOP) imperfection. The second imperfection employed was the out-of-roundness (OOR) imperfection which is the relative initial deviation of the shell wall with respect to the anticipated shell orientation. The amplitudes for the OOR and OOP imperfections were chosen to match the construction tolerances prescribed by API 650. Additional OOR imperfections tolerances suggested by NZSEE were also analyzed for each 
of the tanks. Several conclusion from this study can be drawn and include:

- OOP imperfections are very straightforward to implement into the FEMs. The most critical orientation of the OOP imperfection is when the seismic forces act concurrently with the OOP tilt direction.

- OOR imperfections are much more difficult to assess due to the unlimited imperfection shape and location.

- The effect of the OOP imperfections was seen to decrease the seismic buckling capacity of the tank for each of the tanks in this study. Tank 2 was observed to obtain the highest load reduction with a knock-down factor of 0.92 with respect to the perfect tank condition.

- The effect of OOR imperfections also slightly decreased the seismic buckling capacity of the tank for Tanks 1, 2, and 4 by a maximum amount of $2 \%$, but increased the capacity for Tank 3 by as much as $7 \%$.

- The combined effect of the imperfections occurring concurrently with the seismic loads is highly unlikely but it can be considered as a lower bound solution in terms of seismic capacity. Each of the tanks except Tank 1 experienced a reduction in capacity between 4 and $7 \%$.

- There are both a decrease and increase in the loadcarrying capacity of the tanks with imperfections, in general, with respect to the perfect tanks. It can, therefore, be concluded that the effect of the imperfections is quite sporadic with no definitive trend given that the location of imperfections might not capture the worstcase scenario in all the cases investigated.

- The effect of other types of imperfections, such as weld imperfections, shell thickness imperfections due to corrosion and more random geometrical imperfections of dents and bulges, should be analyzed to determine the effect of the behavior of tanks under seismic forces.

Acknowledgements This study was funded by Purdue University. A special thanks is given to Andres Rondon for providing assistance with implementing the elastic springs into the models [58].

\section{Compliance with ethical standards}

Conflict of interest The authors declare that they have no conflict of interest.
Appendix 1: API 650 and Housner's hoop stress equations in imperial units

$N_{i}=4.5 A_{i} G D H\left[\frac{Y}{H}-0.5\left(\frac{Y}{H}\right)^{2}\right] \tanh \left(0.866 \frac{D}{H}\right) \quad$ For $\mathrm{D} / \mathrm{H} 1.33$

$N_{i}=2.77 A_{i} G D^{2}\left[\frac{Y}{0.75 D}-0.5\left(\frac{Y}{0.75 D}\right)^{2}\right]$

For $\mathrm{D} / \mathrm{H}<1.33, \quad \mathrm{Y}<0.75 \mathrm{D}$

$N_{i}=1.39 A_{i} G D^{2} \quad$ For $\mathrm{D} / \mathrm{H}<1.33, \quad \mathrm{Y} \geq 0.75 \mathrm{D}$

$N_{c}=\frac{0.98 A_{c} G D^{2} \cosh \left[\frac{3.68(H-Y)}{D}\right]}{\cosh \left(\frac{3.68 H}{D}\right)}$

$p_{i}=\frac{\sqrt{3}}{12} A_{i} \gamma_{l} G R H\left[\frac{Y}{H}-0.5\left(\frac{Y}{H}\right)^{2}\right] \tanh \left(\sqrt{3} \frac{R}{H}\right)$

where in the above equations, $\mathrm{N}_{\mathrm{i}}, \mathrm{N}_{\mathrm{c}}$, and $\mathrm{p}_{\mathrm{i}}$ all produce results with units of pounds per inch of shell thickness (lbs/ in). Therefore, to obtain the stress in the shell in psi, the value of $\mathrm{N}_{\mathrm{i}}, \mathrm{N}_{\mathrm{c}^{\prime}}$ and $\mathrm{p}_{\mathrm{i}}$ must be divided by the shell course, in inches, under consideration. Variable descriptions and the units to be used for each of the variables are provided below.

\begin{tabular}{lll}
\hline$A_{c}$ & Convective spectral response parameter & g-forces \\
$A_{i}$ & Impulsive spectral response parameter & $\mathrm{g}$-forces \\
$\mathrm{D}$ & Diameter of the tank & $\mathrm{ft}$ \\
$\mathrm{G}$ & Specific gravity of the liquid & Unitless \\
$\mathrm{H}$ & Height of the tank & $\mathrm{ft}$ \\
$\mathrm{R}$ & Radius of the tank & $\mathrm{ft}$ \\
$\mathrm{Y}$ & Distance from liquid surface to analysis point & $\mathrm{ft}$ \\
$\mathrm{Y}_{\mathrm{I}}$ & Unit weight of water & $\mathrm{Lbs} / \mathrm{ft}^{3}$ \\
\hline
\end{tabular}

\section{Appendix 2: API 650 and Housner's hoop} stress equations in SI units

$N_{i}=8.48 A_{i} G D H\left[\frac{Y}{H}-0.5\left(\frac{Y}{H}\right)^{2}\right] \tanh \left(0.866 \frac{D}{H}\right) \quad$ For $\mathrm{D} / \mathrm{H} \geq 1.33$

$N_{i}=5.22 A_{i} G D^{2}\left[\frac{Y}{0.75 D}-0.5\left(\frac{Y}{0.75 D}\right)^{2}\right]$

For $\mathrm{D} / \mathrm{H}<1.33, \quad \mathrm{Y}<0.75 \mathrm{D}$

$N_{i}=2.6 A_{i} G D^{2} \quad$ For $\mathrm{D} / \mathrm{H}<1.33, \quad \mathrm{Y} \geq 0.75 \mathrm{D}$ 
$N_{c}=\frac{1.85 A_{c} G D^{2} \cosh \left[\frac{3.68(H-Y)}{D}\right]}{\cosh \left(\frac{3.68 H}{D}\right)}$

$p_{i}=\frac{\sqrt{3}}{1000} A_{i} \gamma_{l} G R H\left[\frac{Y}{H}-0.5\left(\frac{Y}{H}\right)^{2}\right] \tanh \left(\sqrt{3} \frac{R}{H}\right)$

where in the above equations, $\mathrm{N}_{\mathrm{i}}, \mathrm{N}_{\mathrm{c}^{\prime}}$ and $\mathrm{p}_{\mathrm{i}}$ all produce results with units of Newtons per millimeter of shell thickness $(\mathrm{N} / \mathrm{mm})$. Therefore, to obtain the stress in the shell in $\mathrm{MPa}$, the value of $\mathrm{N}_{\mathrm{i}}, \mathrm{N}_{\mathrm{c}}$, and $\mathrm{p}_{\mathrm{i}}$ must be divided by the shell course, in $\mathrm{mm}$, under consideration. The variables used in these equations are identical to those provided in "Appendix 1" section. The units to be used for each of the variables are provided below.

\begin{tabular}{lll}
\hline$A_{c}$ & $\begin{array}{c}\text { Convective spectral } \\
\text { response parameter } \\
\text { Impulsive spectral } \\
\text { response parameter }\end{array}$ & $\mathrm{g}$-forces \\
$\mathrm{A}_{\mathrm{i}}$ & $\begin{array}{l}\text { Diameter of the tank } \\
\text { Specific gravity of the }\end{array}$ & $\mathrm{m}$ \\
$\mathrm{D}$ & $\begin{array}{l}\text { Unitless } \\
\text { liquid }\end{array}$ & $\mathrm{m}$ \\
$\mathrm{H}$ & $\begin{array}{l}\text { Height of the tank } \\
\text { Radius of the tank }\end{array}$ & $\mathrm{m}$ \\
$\mathrm{R}$ & $\begin{array}{l}\text { Distance from liquid sur- } \\
\text { face to analysis point }\end{array}$ & $\mathrm{m}$ \\
$\mathrm{Y}$ & Unit weight of water & $\mathrm{N} / \mathrm{m}^{3}$ \\
\hline $\mathrm{Y}_{\mathrm{l}}$ &
\end{tabular}

\section{References}

1. Haroun MA, Housner GW (1981) Earthquake response of deformable liquid storage tanks. J Appl Mech 48(2):411-418

2. Haroun MA, Housner GW (1981) Seismic design of liquid storage tanks. J Tech Counc ASCE 107(1):191-207

3. Housner GW (1957) Dynamic pressures on accelerated fluid containers. Bull Seismol Soc Am 47(1):15-35

4. Housner GW (1963) The dynamic behavior of water tanks. Bull Seismol Soc Am 53(2):381-387

5. American Petroleum Institute (API) (2013) Standard 650, welded steel tanks for oil storage, 12th edn. American Petroleum Institute, Washington, DC

6. Maheri MR, Severn RT (1989) Impulsive hydrodynamic pressures in ground-based cylindrical structures. J Fluids Struct 3(6):555-557

7. Maheri MR, Severn RT (1992) Experimental added-mass in modal vibration of cylindrical structures. Eng Struct 14(3):163-175

8. Malhotra PK (1992) Seismic response of uplifting liquid storage tanks. PhD thesis, Rice University

9. Malhotra PK (1995) Base uplifting analysis of flexibly supported liquid-storage tanks. Earthq Eng Struct Dyn 24(12):1591-1607

10. Malhotra PK (1997) Seismic response of soil-supported unanchored liquid-storage tanks. J Struct Eng ASCE 123(4):440-450
11. Natsiavas S (1988) Analytical model for unanchored fluidfilled tanks under base excitation. J Appl Mech Trans ASME 55(3):648-653

12. Natsiavas S, Babcock CD (1987) Buckling at the top of a fluidfilled tank during base excitation. J Press Vessel Technol Trans ASME 109(4):374-380

13. Natsiavas S, Babcock CD (1988) Behavior of unanchored fluid-filled tanks subjected to ground excitation. J Appl Mech 55(3):654-659

14. Vathi M, Karamanos SA (2014) Modeling of uplifting mechanism in unanchored liquid storage tanks subjected to seismic loading. In: 2nd European conference on earthquake engineering and seismology (ECEES), 24-29 Aug 2014, Istanbul

15. Veletsos AS (1984) Seismic response and design of liquid storage tanks. In: Committee on Gas and Liquid Fuel Lifelines of the ASCE Technical Council on Lifeline Earthquake Engineering (ed) Guidelines for the seismic design of oil and gas pipeline systems. ASCE, New York, pp 255-370

16. Veletsos AS, Auyang J (1977) Earthquake response of liquid storage tanks. In: Advances in civil engineering through engineering mechanics. ASCE, New York, pp 1-24

17. Berahman F, Behnamfar $F$ (2007) Seismic fragility curves for un-anchored on-grade steel storage tanks: Bayesian approach. J Earthq Eng 11(2):166-192

18. El-Zeiny A (1995) Nonlinear time-dependent seismic response of unanchored liquid storage tanks. Dissertation, University of California

19. El-Zeiny A (2004) Simplified modeling of liquid-structure interaction in the seismic analysis of cylindrical liquid storage tanks. In: 13th world conference on earthquake engineering, Vancouver

20. Estekanchi HE, Alembagheri M (2012) Seismic analysis of steel liquid storage tanks by endurance time method. Thin Walled Struct 50(1):14-23

21. Maheri MR, Karbaschi ME, Mahzoon M (2016) Analytical evaluation of dynamic characteristics of unanchored circular ground-based steel tanks. Thin Walled Struct 109(1):251-259

22. Nicolici S, Bilegan RM (2013) Fluid-structure interaction modeling of liquid sloshing phenomena in flexible tanks. Nucl Eng Des 258:51-56

23. Ormeno M, Larkin T, Chouw N (2012) Influence of uplift on liquid storage tanks during earthquakes. Coupled Syst Mech 1(4):311-324

24. Ozdemir Z, Souli M, Fahjan YM (2010) Application of nonlinear fluid-structure interaction methods to seismic analysis of anchored and unanchored tanks. Eng Struct 32(2):409-423

25. Sezen H, Livaoglu R, Dogangun A (2008) Dynamic analysis and seismic performance evaluation of above-ground liquidcontaining tanks. Eng Struct 30(3):794-803

26. Sobhan MS, Rofooei FR, Attari NKA (2017) Buckling behavior of the anchored steel tanks under horizontal and vertical ground motions using static pushover and incremental dynamic analyses. Thin Walled Struct 112(1):173-183

27. Spritzer JM, Guzey S (2017) Review of API 650 Annex E: design of large steel welded aboveground storage tanks excited by seismic loads. Thin Walled Struct 117(1):41-65

28. Spritzer JM, Guzey S (2017) Nonlinear numerical evaluation of large open-top aboveground steel welded liquid storage tanks excited by seismic loads. Thin Walled Struct 119:662-676

29. Virella JC, Suarez LE, Godoy LA (2008) A static nonlinear procedure for the evaluation of the elastic buckling of anchored steel tanks due to earthquakes. J Earthq Eng 12(6):999-1022

30. Wunderlich W, Seiler C (2000) Nonlinear treatment of liquidfilled storage tanks under earthquake excitation by a quasistatic approach. Comput Struct 78(1-3):385-395 
31. New Zealand Society of Earthquake Engineering (NZSEE) (2009) Seismic design of storage tanks: 2009. New Zealand Society of Earthquake Engineering (NZSEE), Wellington

32. Buratti N, Tavano M (2014) Dynamic buckling and seismic fragility of anchored steel tanks by the added mass method. Earthq Eng Struct Dyn 43(1):1-21

33. Phan HN, Paolacci F, Alessandri S (2019) Enhanced seismic fragility analysis of unanchored steel storage tanks accounting for uncertain modeling parameters. J Press Vessel Technol 141(1):010903

34. Bakalis K, Kazantzi AK, Vamvatsikos D, Fragiadakis M (2019) Seismic performance evaluation of liquid storage tanks using nonlinear static procedures. J Press Vessel Technol 141(1):010902

35. Vathi M, Karamanos SA, Kapogiannis IA, Spiliopoulos KV (2017) Performance criteria for liquid storage tanks and piping systems subjected to seismic loading. J Press Vessel Technol 139(5):051801

36. Vathi M, Karamanos SA (2018) A simple and efficient model for seismic response and low-cycle fatigue assessment of uplifting liquid storage tanks. J Loss Prev Process Ind 53:29-44

37. Koiter WT (1945) On the stability of elastic equilibrium. Dissertation, Delft University of Technology; English-translations (a) NASA-TTF-IO. 833 (1967), (b) AFFDL-TR-IO-20 (1970) (translated by E. Riks) (in Dutch)

38. Koiter WT (1980) Buckling of cylindrical shells under axial compression and external pressure: thin shell theory new trends and applications. In: Olszak W (ed) CISM courses and lectures, vol 40. Springer, Wien, pp 77-87

39. Koiter WT, Elishakoff I, Li Y, Starnes JJ (1994) Buckling of an axially compressed imperfect cylindrical shell of variable thickness. In: Proceedings of the 35th AIAA/ASME/ASCE/AHS/ASC structures, structural dynamics and materials conference, Hilton Head. AIAA paper no. 94-1339

40. Godoy LA, Flores FG (2002) Imperfection sensitivity to elastic buckling of wind loaded open cylindrical tanks. Struct Eng Mech 13(5):533-542

41. Rotter JM (1985) Buckling of ground-supported cylindrical steel bins under vertical compressive wall loads. In: Proceeding of the metal structures conference. Institution of Engineers of Australia, Melbourne, pp 112-127

42. Rotter JM (2009) Silos and tanks in research and practice: state of the art and current challenges. Editorial Universitat Politècnica de València, pp 65-76

43. Teng JG, Rotter JM (2006) Buckling of thin metal shells. CRC Press, London

44. Veletsos AS, Turner JW (1978) Effects of initial out-of-roundness on seismic response of cylindrical liquid storage tanks. Rice University, Houston
45. Djermane M, Zaoui D, Labbaci B, Hammadi F (2014) Dynamic buckling of steel tanks under seismic excitation: numerical evaluation of code provisions. Eng Struct 70:181-196

46. ABAQUS (2016) Abaqus analysis user's manual version 2016. Dassault Systemes Simulia Corp., Providence

47. ASTM (2015) A516/A516M-10 standard specification for pressure vessel plates, carbon steel, for moderate- and lower-temperature service. ASTM International, West Conshohocken

48. ASTM (2014) A36/A36M-14 standard specification for carbon structural steel. ASTM International, West Conshohocken

49. American Society of Civil Engineers (ASCE) (2013) Minimum design loads for buildings and other structures (ASCE/SEI 7-10), Third Printing edn. American Society of Civil Engineers, Reston

50. United States Geological Survey (USGS) (2011) Worldwide seismic design tool (beta). http://earthquake.usgs.gov/hazards/ designmaps/

51. ASTM (2011) D1586-11 standard test method for standard penetration test (SPT) and split-barrel sampling of soils. ASTM International, West Conshohocken

52. Bohra H, Azzuni E, Guzey S (2019) Seismic analysis of open-top storage tanks with flexible foundation. J Press Vessel Technol 141(4):041801

53. American Society of Mechanical Engineers (ASME) (2015) Boiler and pressure vessel code, Section VIII, alternative rules for construction of pressure vessels, division 2. American Society of Mechanical Engineers, New York

54. Riks E (1979) An incremental approach to the solution of snapping and buckling problems. Int J Solids Struct 15(7):529-551

55. Taniguchi T, Ando Y, Nakashima T (2009) Fluid pressure on unanchored rigid flat-bottom cylindrical tanks due to uplift motion and its approximation. Eng Struct 31(11):2598-2606

56. Building Seismic Safety Council (2015) NEHRP recommended seismic provisions for new buildings and other structures, part 1 provisions, part 2 commentary. FEMA rept. no. P-1050-1, Washington, DC

57. European Committee for Standardization (2007) Eurocode 3: design of steel structure-part 4-1: silos. Standard No. EN 19934-1. European Committee for Standardization, Brussels

58. Rondon R, Guzey S (2017) Failure pressure of the API specification $12 \mathrm{~F}$ shop welded, flat bottom tanks. ASME J Press Vessel Technol 139(4):041409-041409-18

Publisher's Note Springer Nature remains neutral with regard to jurisdictional claims in published maps and institutional affiliations. 